\title{
Article \\ Physiological and Molecular Responses of 'Dusa' Avocado Rootstock to Water Stress: Insights for Drought Adaptation
}

\author{
Moreno-Ortega Guillermo ${ }^{1,2}$, Zumaquero Adela ${ }^{1}$, Matas Antonio ${ }^{3}{ }^{(0}$, Nicholas A. Olivier ${ }^{4}{ }^{(}$,

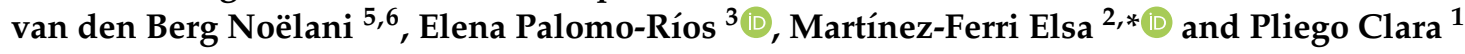

1 Departamento de Genómica y Biotecnología, Fruticultura Subtropical y Mediterránea (IFAPA) Unidad Asociada de I+D+i al CSIC, Cortijo de la Cruz s/n, 21940 Churriana, Spain; guillermo.moreno.o@juntadeandalucia.es (M.-O.G.); zumaquero@uma.es (Z.A.); mclara.pliego@juntadeandalucia.es (P.C.)

2 Departamento de Ecofisiología de Cultivos, Fruticultura Subtropical y Mediterránea (IFAPA) Unidad Asociada de I+D+i al CSIC, Cortijo de la Cruz s/n, 21940 Churriana, Spain

3 Departamento de Botánica y Fisiología Vegetal, Instituto de Hortofruticultura Subtropical y Mediterránea "La Mayora" (IHSM-UMA-CSIC), Unidad Asociada IHSM-IFAPA, Universidad de Málaga, 29071 Málaga, Spain; antoniojmatas@uma.es (M.A.); epalomorios@uma.es (E.P.-R.)

4 Department of Plant and Soil Science, University of Pretoria, Pretoria 0002, South Africa; nicky.olivier@fabi.up.ac.za

5 Department of Biochemistry, Genetics and Microbiology, University of Pretoria, Pretoria 0002, South Africa; noelani.vandenberg@up.ac.za

Citation: Guillermo, M.-O.; Adela, Z.; Antonio, M.; Olivier, N.A.; Noëlani, v.d.B.; Palomo-Ríos, E.; Elsa, M.-F.; Clara, P. Physiological and Molecular Responses of 'Dusa' Avocado Rootstock to Water Stress: Insights for Drought Adaptation. Plants 2021, 10, 2077. https:// doi.org/10.3390/plants10102077

Academic Editors: Pirjo Mäkelä,

Mercè Llugany, Peter A. Roussos and Mumtaz Cheema

Received: 1 September 2021

Accepted: 26 September 2021

Published: 30 September 2021

Publisher's Note: MDPI stays neutral with regard to jurisdictional claims in published maps and institutional affiliations.

Copyright: (c) 2021 by the authors. Licensee MDPI, Basel, Switzerland. This article is an open access article distributed under the terms and conditions of the Creative Commons Attribution (CC BY) license (https:/ / creativecommons.org/licenses/by/ $4.0 /)$.
6 Forestry and Agricultural Biotechnology Institute (FABI), University of Pretoria, Pretoria 0002, South Africa

* Correspondence: elsa.martinez@juntadeandalucia.es
Abstract: Avocado consumption is increasing year by year, and its cultivation has spread to many countries with low water availability, which threatens the sustainability and profitability of avocado orchards. However, to date, there is not much information on the behavior of commercial avocado rootstocks against drought. The aim of this research was to evaluate the physiological and molecular responses of 'Dusa' avocado rootstock to different levels of water stress. Plants were deficit irrigated until soil water content reached 50\% (mild-WS) and 25\% (severe-WS) of field capacity. Leaf water potential $\left(\Psi_{\mathrm{w}}\right)$, net $\mathrm{CO}_{2}$ assimilation rates $\left(A_{\mathrm{N}}\right)$, transpiration rate $(E)$, stomatal conductance $\left(g_{\mathrm{s}}\right)$, and plant transpiration rates significantly decreased under both WS treatments, reaching significantly lower values in severe-WS plants. After rewatering, mild- and severe-WS plants showed a fast recovery in most physiological parameters measured. To analyze root response to different levels of drought stress, a cDNA avocado stress microarray was carried out. Plants showed a wide transcriptome response linked to the higher degree of water stress, and functional enrichment of differentially expressed genes (DEGs) revealed abundance of common sequences associated with water stress, as well as specific categories for mild-WS and severe-WS. DEGs previously linked to drought tolerance showed overexpression under both water stress levels, i.e., several transcription factors, genes related to abscisic acid (ABA) response, redox homeostasis, osmoprotection, and cell-wall organization. Taken altogether, physiological and molecular data highlight the good performance of 'Dusa' rootstock under low-water-availability conditions, although further water stress experiments must be carried out under field conditions.

Keywords: Persea americana; abiotic stress; water deprivation; microarray

\section{Introduction}

Among all environmental factors representing a threat to agricultural production, drought has the largest impact on crop productivity [1]. Drought occurs in almost all climatic regions, and it induces crop yield loss in a wide range of plants, while also increasing global tree mortality [2]. Predicted scenarios of climate change suggest that regions, such as the Mediterranean basin, which includes the subtropical Andalusian coast, 
might be especially vulnerable to global warming and drought [3], calling into question the long-term sustainability of certain crops. Therefore, characterizing plants' responses to water stress is needed to provide insight into drought effects on plants and elucidate the mechanisms to recognize external stress signals that trigger changes from physiological to molecular levels, which finally lead to a decrease in crop yield.

Avocado (Persea americana Mill.) is considered one of the most nutritional fruits [4], whose consumption is increasing year by year. Its cultivation has spread to many countries from the tropics to the Mediterranean region, facing low-water-availability environments. In this scenario, the sustainability and profitability of the avocado crop should rely on a better use of water [5] and the selection of drought-tolerant avocado rootstocks. However, to date most of the rootstock selections have focused on root rot and salinity tolerance, and there is not much information on the behavior of commercial avocado rootstocks under drought stress situations. The avocado rootstock 'Dusa' was commercially released in 2004 and it has replaced previous selections such as 'Duke 7', becoming the most extensively used clonal rootstock worldwide [6]. Well adapted to temperate and subtropical climates, 'Dusa' has shown excellent behavior against Phytophthora cinnamomi [7], resistance to Verticillium dahliae [8], an acceptable tolerance to salinity [9], and graft compatibility with many scions, giving rise to high-yielding combinations [10]. However, to date, there is no report dealing with the physiological and molecular response of 'Dusa' to water stress.

Understanding the molecular mechanisms underlying drought stress tolerance has been an active area of research, and recent transcriptome studies have identified many genes related to drought stress responses in plants [11-16], including those encoding detoxification enzymes, osmoprotectants, heat-shock proteins (HSPs), and phytohormones. In addition, several genes encoding transcription factors (TFs) that regulate and provide adaptive responses to water stress have been identified such as NAC, WRKY, MYB, and $\mathrm{bZIP}$, and some of them have been engineered to improve stress tolerance in model and crop plants $[17,18]$. Despite the development of next-generation sequencing leading to considerable progress, the molecular mechanisms underpinning drought tolerance are not yet fully elucidated. In addition, reports in different species point to the existence of both conserved and species-specific drought-inducible genes, suggesting the complex nature of the drought stress response [19].

The aim of this study was to shed light on the mechanisms underlying the response of 'Dusa' avocado rootstock to different levels of water stress via a combination of physiological measurements and gene expression analysis. Molecular studies were carried out using an Agilent array specifically designed to study the gene expression profiles of 'Dusa' rootstocks subjected to biotic $[20,21]$ and abiotic stresses [20]. Evaluating the response of 'Dusa' to different levels of water stress will provide key information for subsequent investigations related to the improvement of water use efficiency and drought tolerance in avocado.

\section{Results and Discussion}

\subsection{Physiological Response to Drought Stress and Rewatering}

To investigate the physiological response of 'Dusa' rootstock to water stress, plants were deficit irrigated until soil water content (SWC) reached 50\% (i.e., mild-WS) and $25 \%$ (i.e., severe-WS) of field capacity $(\mathrm{Fc})$. Once these levels were reached, rewatering was carried out, and Fc values were attained immediately (Figure 1). A set of physiological measurements were taken at the leaf and whole-plant levels to assess the response of 'Dusa' to each level of water stress and rewatering. 


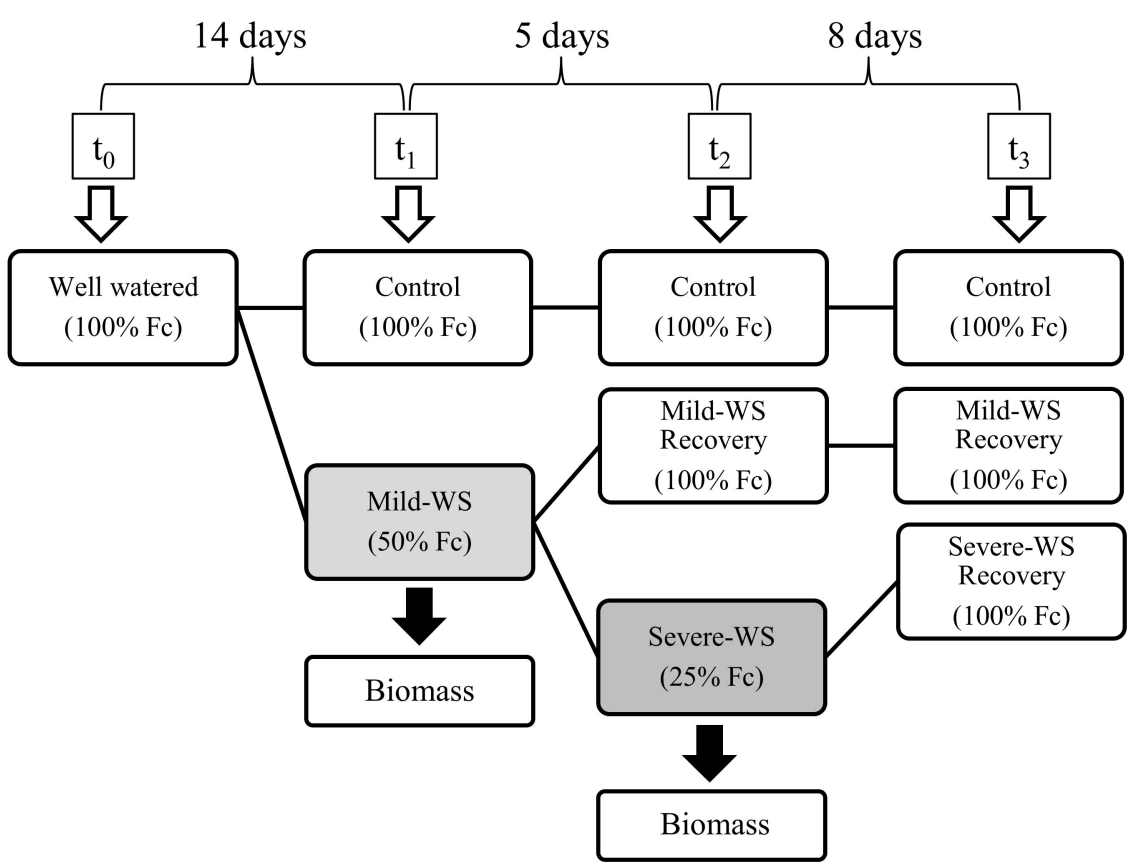

Figure 1. Schematic illustration of the experimental design. Control plants were maintained at field capacity $\left(\mathrm{Fc}_{\mathrm{c}}\right)$ throughout the experiment, and water-stressed plants were subjected to substrate drying-up until they reached $50 \%$ of Fc (mild-WS; $t_{1}$ ) and $25 \%$ of Fc (severe-WS; $t_{2}$ ), respectively. Subsequently, plants were fully irrigated to assess the drought recovery response $\left(t_{2}\right.$ and $\left.t_{3}\right)$.

The soil moisture of water-stressed plants decreased from field capacity $(\sim 0.4 v / v)$ to $\sim 0.2 v / v$ in mild-WS in 14 days $\left(t_{1}\right)$ and, 5 days later $\left(t_{2}\right)$, to $\sim 0.1 v / v$ in severe-WS (Figure 2A). These changes in SWC were translated into significantly lower values of leaf relative water content (RWC) in mild-WS and severe-WS $(89.65 \% \pm 0.81 \%$ and $88.37 \% \pm 1.54 \%$, respectively) compared to those of control plants (between $92.25 \% \pm 0.44 \%$ and $96.72 \% \pm 0.44 \% ; p<0.05$; Figure $2 \mathrm{~B}$ ), but RWC values did not match stress severity. In contrast to RWC, predawn and midday leaf water potential $\left(\Psi_{\mathrm{W}}\right)$ values of water-stressed plants decreased significantly in comparison with control plants $(p<0.05)$ and accordingly with the soil water depletion (Figure 2C,D), supporting the use of this parameter as an appropriate plant-based water stress indicator in avocado [5,22]. Despite both treatments reaching values of predawn and midday leaf water potential indicative of drought stress [23-25], water-stressed plants recovered control values within 5-8 days of rewatering, which possibly indicates the robustness of the water transport system in 'Dusa' plants. This fast recovery could be related to specific anatomical vessel features associated with the low vulnerability to cavitation reported in Guatemalan and Mexican avocado races [26], from which 'Dusa' is a hybrid. This hypothesis is consistent with the relationship between a fast recovery of water potential values with water transport via remaining intact xylem conduits in another woody species [27].

Net $\mathrm{CO}_{2}$ assimilation rate $\left(A_{\mathrm{N}}\right)$, transpiration rate $(\mathrm{E})$, and stomatal conductance $\left(g_{\mathrm{s}}\right)$ showed a marked and significant decrease in both water stress levels $(p<0.05$; Figure $2 \mathrm{E}-\mathrm{G})$. Mild-WS involved a decrease in gas exchange parameters $\left(A_{\mathrm{N}}, E\right.$, and $\left.g_{\mathrm{s}}\right)$ of around $80-88 \%$ compared to control values, while severe-WS caused a reduction of $95-97 \%$. Stomatal closure to avoid water losses through transpiration and the resulting decrease in assimilation rates are common plant responses to water stress [28,29]. Water-stressed avocado plants were able to maintain certain $\mathrm{CO}_{2}$ assimilation rates despite the low stomatal conductance values. This led to higher intrinsic water use efficiency $\left(A_{\mathrm{N}} / g_{\mathrm{s}}\right)$ in both levels of water stress compared to control plants, with mild-WS plants displaying higher values (Figure $2 \mathrm{H}$ ). All gas exchange parameters were recovered up to control values after rewatering regardless of water stress severity, but it is remarkable that severely water-stressed avocado plants 
recovered even faster than mild-WS ones (5 and 10 days, respectively), which is in contrast with the long-lasting recovery commonly associated with increased levels of water stress [27]. In this sense, it should be noted that, although soil-water depletion in plants with mild-WS was lower than in those with severe-WS, in the former, the level of stress was maintained for 9 days before measurements (Figure 2), which can account for the small differences between the water treatments observed in the response to water stress.

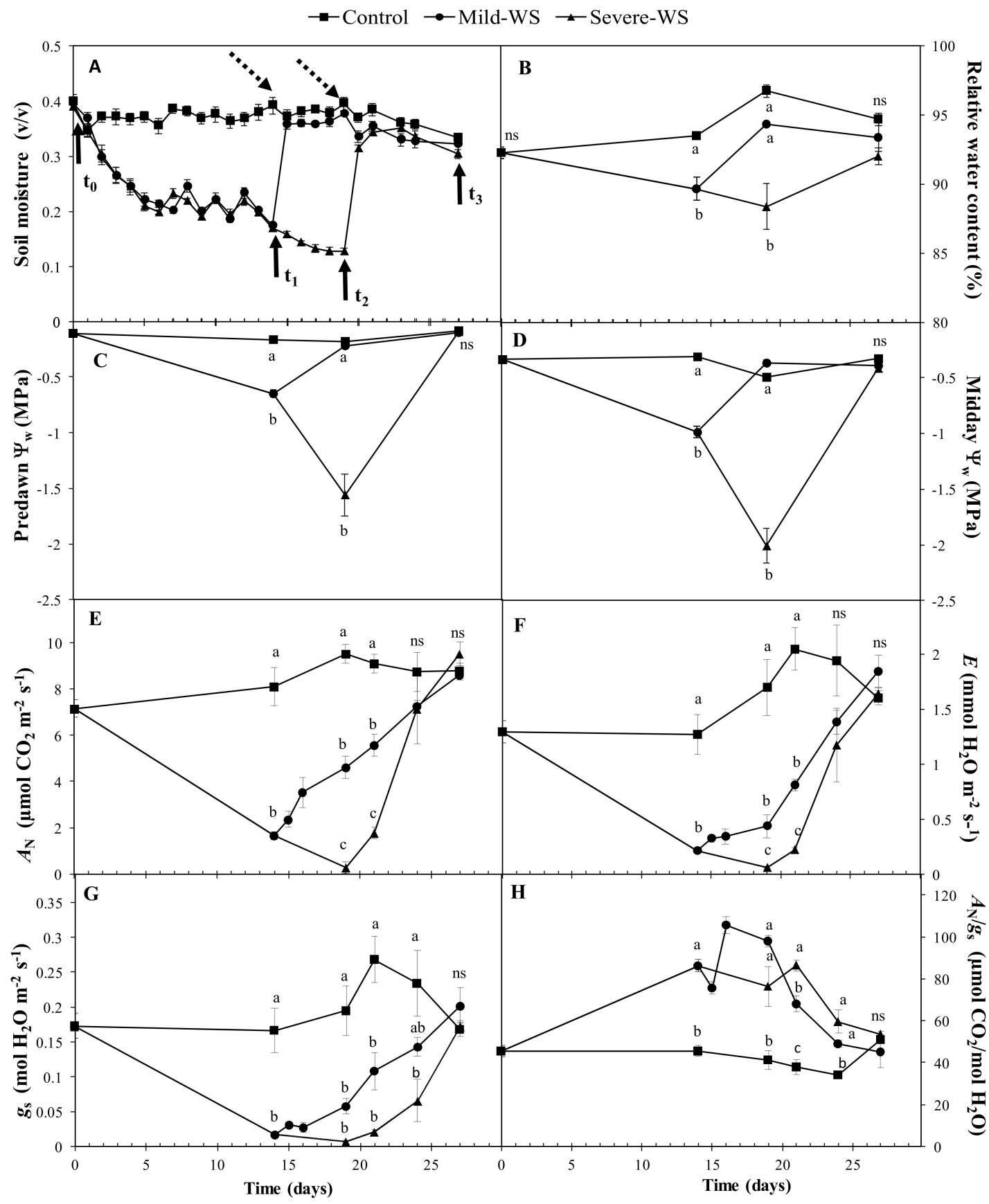

Figure 2. Time-course of mean values ( $\pm \mathrm{SE} ; n=4$ to 16$)$ of volumetric soil moisture (A), relative water content (B), predawn $(\mathbf{C})$ and midday leaf water potential $\left(\Psi_{\mathrm{W}} ; \mathbf{D}\right)$, net $\mathrm{CO}_{2}$ assimilation rate $\left(A_{\mathrm{N}} ; \mathbf{E}\right)$, transpiration rate $(E ; \mathbf{F})$, stomatal conductance $(g \mathrm{~s} ; \mathrm{G})$, and intrinsic water use efficiency $\left(A_{\mathrm{N}} / g_{\mathrm{s}} ; \mathbf{H}\right)$ of 'Dusa' plants subjected to three water treatments: control, mild-WS (50\% Fc), and severe-WS (25\% Fc). Solid arrows indicate the timepoints where measurements and samplings were done, while dotted arrows show rewatering days. Different letters indicate significant differences among treatments for the specific timepoints (days) ( $p<0.05$; ns: no statistical differences). 
Nevertheless, the faster recovery of $A_{\mathrm{N}}$ in comparison to $g_{\mathrm{s}}$, resulting in higher values of $A_{\mathrm{N}} / g_{\mathrm{s}}$ after rewatering, in both levels of water stress, suggests that the drought-induced decrease in photosynthesis was mainly mediated by stomatal limitations [30,31]. This mismatching response has already been described in other woody species [32,33] and is the basis for suggesting the use of deficit irrigation strategies for increasing crop water use efficiency [34]. It is feasible to conclude that the fast and complete recovery of all gas exchange parameters at both levels of water stress indicate a lack of persistent damage in the photosynthetic apparatus. This is supported by the absence of significant differences in the relative chlorophyll content (SPAD index) indicating that no chlorophyll degradation was associated with any of the water stress treatments (average value of SPAD index was $65.9 \pm 0.9$ in all treatments) and by the high predawn photochemical efficiency of PSII $\left(F_{\mathrm{v}} / F_{\mathrm{m}}\right)$ of all plants regardless of the water treatment (average $F_{\mathrm{v}} / F_{\mathrm{m}}$ was $0.8 \pm 0.04$ in all treatments).

The set of changes at the leaf level in response to water stress (Figures 2 and 3A) were accompanied by adjustments at the whole-plant level. Plant transpiration rate was significantly lower $(p<0.05$; Figure 3B) in both levels of water stress, showing $42 \%$ and $86 \%$ of control values in mild-WS and severe-WS, respectively. Consistently, plant hydraulic conductance $\left(\mathrm{K}_{\mathrm{h}}\right)$ was also affected in both water stress treatments, being significantly lower in severe-WS ( $p<0.05$; Figure $3 \mathrm{C}$ ). After rewatering, $\mathrm{K}_{\mathrm{h}}$ recovered near-control values but plant transpiration rate in severe-WS was still significantly lower than that in control plants. Since SWC and leaf water potential were fully restored after rewatering, the persistence of the lower plant transpiration rates could indicate some degree of embolized conduits associated with severe drought stress [35]. In this sense, the significantly higher root amount in water-stressed plants $(p<0.05$, Table 1$)$ was not enough to counteract the negative effects of severe-WS on $K_{h}$ after rewatering. This suggests that this plant hydraulic impairment might result from disorders either at the trunk or at the root level, since roots are typically more vulnerable than shoots to cavitation, being the weakest link along the hydraulic flow path from soil to atmosphere under drought stress [36,37].

The significantly higher root/shoot ratio ( $p<0.05$, Table 1$)$ observed in mild-WS and severe-WS plants is consistent with previous findings in drought-tolerant genotypes, where an increase in the ratio of root biomass to aerial parts was observed in response to water stress [38]. It is interesting to note that root growth induced by water deprivation occurred in a short period (14 and 19 days in mild-WS and severe-WS, respectively), suggesting a fast adaptative strategy of 'Dusa' to cope with drought stress.

\subsection{Transcriptional Responses of 'Dusa' Avocado Rootstock Subjected to Mild and Severe Water Stress}

Water stress affects several biological processes, and plants must change their global gene expression patterns to survive water shortage. Since soil water limitation is initially detected by the roots, characterizing the differentially expressed genes (DEGs) in response to different levels of water stress is critical to understand the molecular basis of drought tolerance. To analyze the avocado response to water shortage, a targeted cDNA avocado stress microarray [10] containing transcripts from de novo sequencing of 'Dusa' in response to biotic and abiotic stress [20] was used. Root samples were collected at $t_{1}$ and $t_{2}$ corresponding to mild-WS and severe-WS, respectively (Figure 1 ). The hybridization percentages of the microarrays were similar for the two timepoints, being $78.32 \%$ for mildWS and $76.59 \%$ for severe-WS. The total number of DEGs on the array was $549(47.2 \%$ induced and 52.8\% repressed) and 1066 (40.4\% induced and 59.6\% repressed) in mild-WS and severe-WS, respectively $(-2>$ fold change $(\mathrm{FC})>2 ; p<0.05)$. As shown in Figure 4,189 genes were specific to mild-WS and 706 were specific to severe-WS. The increased number of DEGs observed in severe-WS is in agreement with other transcriptome studies in which a higher degree of water stress involves a wider transcriptome response [12,16]. Regarding the overall response to water deprivation in avocado, there were more downregulated than upregulated genes. Similar results have previously been observed in other crops subjected to drought stress $[14,16,39-44]$. 


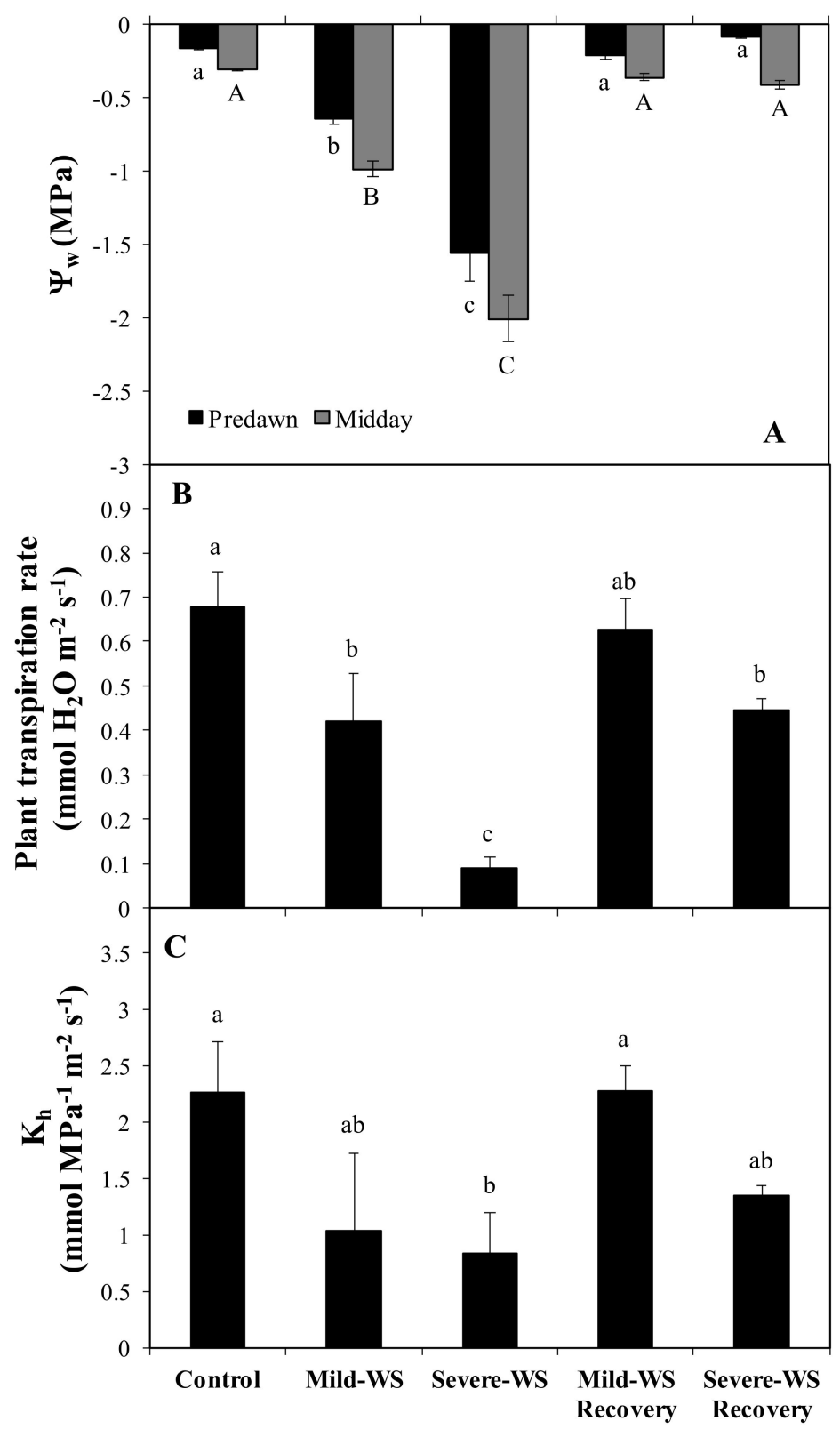

Figure 3. Predawn and midday water potential $(\Psi \mathrm{w} ; \mathbf{A})$, plant transpiration rate (B), and plant hydraulic conductance $\left(K_{\mathrm{h}} ; \mathrm{C}\right)$ from 'Dusa' avocado rootstock subjected to two different levels of water stress: mild-WS ( $50 \%$ of $\mathrm{FC}_{\mathrm{C}}$ ) and severe-WS $\left(25 \%\right.$ of $\mathrm{Fc}_{\mathrm{C}}$ (mean $\left.\pm \mathrm{SE} ; n=4\right)$ and their corresponding recovery. Within each series, different capital or lowercase letters indicate significant differences among treatments $(p<0.05)$.

\subsection{Validation of the Microarray}

Differences found in gene expression profiles between mild-WS and severe-WS were further verified by performing a real-time quantitative qPCR (qRT-PCR) assay on total cDNA samples from roots of three biological replicates. Thirteen unigenes showing contrasting expression patterns among mild-WS and severe-WS were analyzed. Negative controls were used to confirm the absence of contamination and actin was used as a reference gene for data normalization. The expression levels of these genes amplified by qRT-PCR are shown in Table 2. The results corroborated the overall differences found among mild-WS and severe-WS in the microarray analysis. 
Table 1. Plant dry biomass parameters and leaf mass area (LMA) from 'Dusa' avocado rootstock under two different levels of water stress: mild-WS ( $50 \%$ of $\mathrm{FC}_{\mathrm{C}}$ ) and severe-WS ( $25 \%$ of Fc). The table shows mean values $( \pm \mathrm{SE} ; n=4)$ under stress and after the corresponding recovery. Different letters indicate significant differences among treatments $(p<0.05$, ns: no statistical differences).

\begin{tabular}{|c|c|c|c|c|c|c|c|c|c|c|}
\hline \multirow[b]{2}{*}{ Plant dry biomass (g) } & \multicolumn{2}{|l|}{ Control } & \multicolumn{2}{|l|}{ Mild-WS } & \multicolumn{2}{|c|}{ Severe-WS } & \multicolumn{2}{|c|}{ Mild-WSRecovery } & \multicolumn{2}{|c|}{ Severe-WSRecovery } \\
\hline & $567.94 \pm 63.76$ & ns & $504.08 \pm 64.02$ & ns & $554.43 \pm 38.84$ & ns & $572.93 \pm 77.63$ & ns & $571.70 \pm 30.88$ & ns \\
\hline Leaf dry biomass (\%) & $29.09 \pm 2.74$ & ns & $21.26 \pm 2.18$ & ns & $23.30 \pm 2.57$ & ns & $29.87 \pm 1.96$ & ns & $23.09 \pm 2.57$ & ns \\
\hline Stem dry biomass (\%) & $43.69 \pm 1.45$ & ns & $41.46 \pm 2.07$ & ns & $39.00 \pm 2.27$ & ns & $38.91 \pm 0.82$ & ns & $39.30 \pm 0.37$ & ns \\
\hline Root dry biomass (\%) & $27.22 \pm 2.60$ & $\mathrm{~b}$ & $37.28 \pm 0.95$ & $\mathrm{a}$ & $37.70 \pm 2.45$ & a & $31.22 \pm 2.42$ & $\mathrm{ab}$ & $37.61 \pm 2.60$ & a \\
\hline Root /shoot ratio & $0.38 \pm 0.05$ & $\mathrm{~b}$ & $0.60 \pm 0.02$ & a & $0.61 \pm 0.06$ & a & $0.46 \pm 0.05$ & $\mathrm{ab}$ & $0.61 \pm 0.06$ & a \\
\hline $\begin{array}{l}\text { Leaf mass area } \\
\left(\mathrm{g} \cdot \mathrm{m}^{-2}\right)\end{array}$ & $98.76 \pm 3.09$ & $\mathrm{ab}$ & $90.05 \pm 1.52$ & $\mathrm{~b}$ & $74.17 \pm 5.50$ & c & $104.17 \pm 6.78$ & a & $86.90 \pm 6.92$ & $\mathrm{bc}$ \\
\hline
\end{tabular}

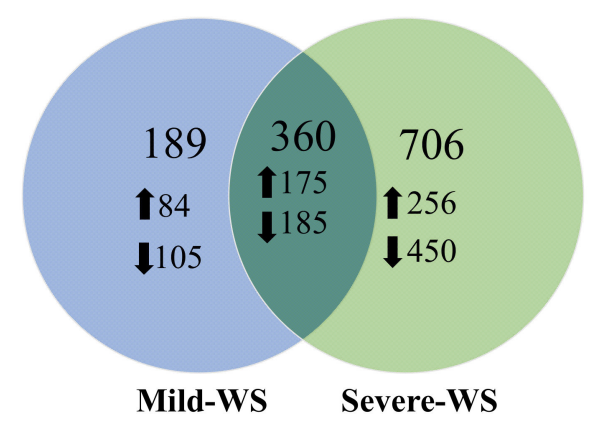

Figure 4. Venn diagram of differentially expressed genes. Numbers of common and specific differentially expressed genes (DEGs) obtained in the microarray analysis of 'Dusa' avocado rootstocks subjected to two different levels of water stress (50\% of Fc, mild-WS and $25 \%$ of Fc, severe-WS). Statistically significant DEGs $(p<0.05)$ were filtered above and below fold change values of 2 and -2 , respectively. Unique DEGs are shown only in one of the two circles, while shared transcripts are shown in their intersection. Arrows indicate the number of genes up- and downregulated.

Table 2. qRT-PCR and microarray expression data of selected contigs from 'Dusa' avocado rootstock under two different levels of water stress: mild-WS ( $50 \%$ of Fc) and severe-WS ( $25 \%$ of Fc). Numbers in bold indicate statistically significant results $(p<0.05)$.

\begin{tabular}{|c|c|c|c|c|c|}
\hline \multirow[b]{2}{*}{ Annotation } & \multirow[b]{2}{*}{ Contig } & \multicolumn{2}{|c|}{ Mild-WS } & \multicolumn{2}{|c|}{ Severe-WS } \\
\hline & & $\begin{array}{c}\text { Microarray } \\
\text { FC }\end{array}$ & $\begin{array}{l}\text { q-RT } \\
\text { FC }\end{array}$ & $\begin{array}{c}\text { Microarray } \\
\text { FC }\end{array}$ & $\begin{array}{l}\text { q-RT } \\
\text { FC }\end{array}$ \\
\hline PR5 & Pa_Contig01462 & 2.80 & 4.06 & 6.10 & 7.24 \\
\hline Profilin 1 isoform 1 & Pa_Contig02273 & 1.07 & 1.39 & -1.10 & -1.22 \\
\hline Protease inhibitor II & Pa_Contig03907 & -1.20 & -1.68 & 2.12 & 4.31 \\
\hline Alcohol dehydrogenase $b$ & Pa_Sin_GI32N0T02IUGTU & 1.04 & 1.61 & -1.05 & -2.00 \\
\hline LRR resistance PLP & Pa_Contig01244 & 1.06 & 1.39 & -1.12 & -1.22 \\
\hline Trypsin inhibitor & Pa_Contig04097 & -2.39 & -1.18 & 1.16 & 1.51 \\
\hline Sucrose synthase & Pa_Contig00004 & -1.83 & -2.22 & -1.54 & -1.44 \\
\hline Phenylalanine ammonia-lyase (PAL) & Pa_Contig00410 & -1.00 & -1.59 & -1.41 & -1.51 \\
\hline Chalcone synthase & Pa_Contig00619 & -1.50 & -3.54 & -3.02 & -6.10 \\
\hline $\begin{array}{c}\text { Xyloglucan endotransglucosylase } \\
\text { hydrolase }\end{array}$ & Pa_Contig00751 & -2.04 & -4.63 & -2.71 & -7.94 \\
\hline Defensin j1-2-like & Pa_Contig04185 & -1.99 & -2.32 & -2.04 & -1.33 \\
\hline Lipoxygenase (LOX) & Pa_Contig04337 & -1.74 & -2.29 & -1.85 & -4.15 \\
\hline PR4 & Pa_Contig06278 & -3.28 & -2.67 & -3.78 & -5.60 \\
\hline
\end{tabular}




\subsection{Functional Annotation and GO Term Enrichment Analysis of the Differentially Expressed} Genes (DEGs) of 'Dusa' Avocado Roots Subjected to Mild and Severe Water Stress

To better understand the transcriptional responses under different levels of drought stresses, all DEGs were functionally enriched and categorized on the basis of blast sequence homologies and Gene Ontology (GO) annotations using Blast2GO software $(p<0.05)$ (Figure 5).
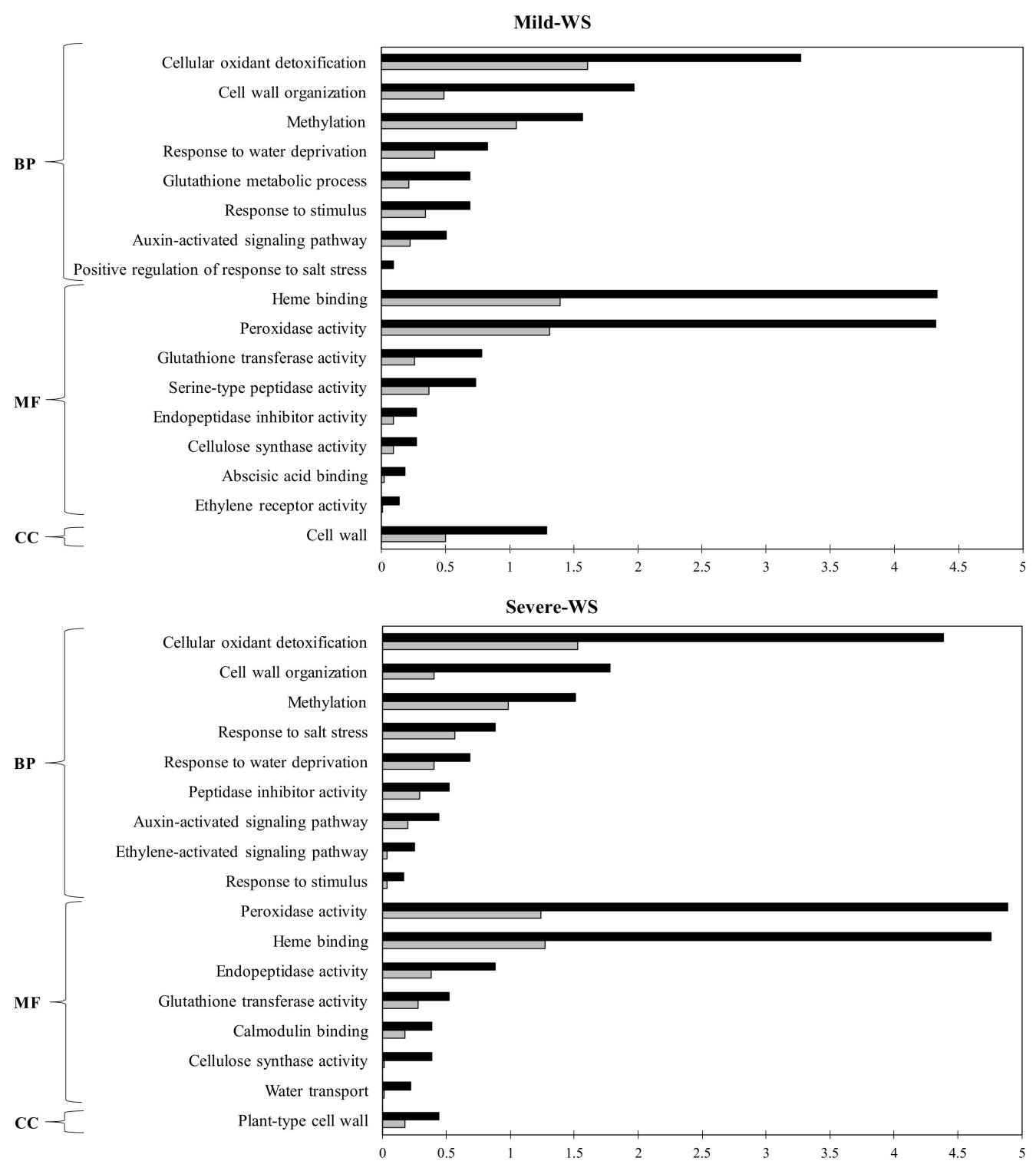

Figure 5. Gene Ontology (GO) enrichment analysis of differentially expressed genes (DEGs) in the microarray analysis of 'Dusa' avocado rootstocks subjected to two different levels of water stress: mild-WS ( $50 \%$ of $\mathrm{Fc}_{\mathrm{c}}$ ) and severe-WS ( $25 \%$ of $\mathrm{Fc}_{\mathrm{c}}$ ). Enrichment GO terms were obtained by Blast2GO $(p<0.05)$. BP, biological process; MF, molecular function; CC, cellular component. Black bars represent test set (mild and severe-WS) while gray bars represent the reference set.

DEGs were significantly grouped into the regulation of eight biological processes (BPs), eight molecular functions (MFs), and one cellular component (CC) for mild-WS treatment, and nine BPs, seven MFs, and one CC for severe-WS.

Six subcategories, belonging to the BP category, were shared by mild-WS and severeWS, in which "cellular oxidant detoxification" (GO:0098869), followed by "cell-wall organization" (GO:0071555), "methylation" (GO:0032259), and "response to water deprivation" (GO:0009414) were among the most represented ones. These subcategories are widely asso- 
ciated with plant response to drought stress and subsequent cellular modification [45-47]. Interestingly, the "response to water deprivation" (GO:0009414) subcategory included DEGs involved in responses to the two types of stress, biotic and abiotic, i.e., calmodulin binding protein (Pa_Contig02689) [48], proteinase inhibitor (Pa_Contig00984) [49], methionine gamma-lyase (Pa_Contig00456) [50], and mitogen-activated protein kinase (Pa_Contig00290) [51]. The GO term "response to salt stress" (GO:0009651) included DEGs encoding heat-shock-like proteins (HSPs), (i.e., Pa_Contig01858, Pa_Contig02550, Pa_Contig06453, Pa_Sin_FZ03KKT01BNH1K, Pa_Sin_HA66E9C01AHKXT, Pa_Sin_HA66E 9C01ALALK, Pa_Sin_HA66E9C01ARY1I, and Pa_Sin_HA66E9C01BA3Q), known to perform an essential role in plant protection against abiotic stress [52] by preventing undesired protein-protein interactions and assisting refolding of denatured proteins [53]. Among them, the I HSP class (Pa_Sin_FZ03KKT01BNH1K) was the most overexpressed gene in both mild-WS and severe-WS (Table 3).

Table 3. Top 20 induced and top 20 repressed differentially expressed genes (DEGs) from 'Dusa' avocado rootstock subjected to two different levels of water stress: mild-WS ( $50 \%$ of Fc) and severe-WS ( $25 \%$ of Fc) (NA, nonannotated; FC, fold change).

\begin{tabular}{|c|c|c|c|c|c|}
\hline \multicolumn{3}{|c|}{ Mild-WS } & \multicolumn{3}{|c|}{ Severe-WS } \\
\hline Name & Description & FC & Name & Description & FC \\
\hline Pa_Sin_FZ03KKT01BNH1K & $\begin{array}{l}\text { 18.1 kDa class I heat-shock } \\
\text { protein-like }\end{array}$ & 28.94 & Pa_Sin_FZ03KKT01BNH1K & $\begin{array}{c}18.1 \mathrm{kDa} \text { class I heat-shock } \\
\text { protein-like }\end{array}$ & 23.07 \\
\hline Pa_Sin_HA66E9C01BSEGX & $\begin{array}{c}\text { Splicing factor SF3a60 } \\
\text { homolog }\end{array}$ & 22.31 & Pa_Contig05542 & NA & 21.08 \\
\hline Pa_Contig03188 & $\begin{array}{c}\text { Transmembrane protein } \\
\text { TauE-like }\end{array}$ & 19.52 & Pa_Sin_GI32N0T02G3V3U & $\begin{array}{l}\text { DExH-box ATP-dependent } \\
\text { RNA helicase DExH3 }\end{array}$ & 14.81 \\
\hline Pa_Contig03520 & $\begin{array}{c}\text { Transmembrane protein } \\
\text { TauE-like }\end{array}$ & 18.46 & Pa_Contig03188 & $\begin{array}{c}\text { Transmembrane protein } \\
\text { TauE-like }\end{array}$ & 13.97 \\
\hline Pa_Sin_GI32N0T02J3CHK & $\begin{array}{c}\text { PREDICTED: } \\
\text { uncharacterized protein } \\
\text { LOC103961965 }\end{array}$ & 14.94 & Pa_Sin_HA66E9C01AIWJ3 & $25.3 \mathrm{kDa}$ heat-shock protein & 12.05 \\
\hline Pa_Contig02835 & Probable nucleoredoxin 2 & 14.42 & Pa_Contig03520 & $\begin{array}{c}\text { Transmembrane protein } \\
\text { TauE-like }\end{array}$ & 11.97 \\
\hline Pa_Contig05542 & NA & 13.94 & Pa_Sin_GI32N0T02IBYBH & Phospholipase D beta 1 & 11.80 \\
\hline Pa_Contig00313 & $\begin{array}{l}\text { NAC domain-containing } \\
\text { protein } 72\end{array}$ & 12.71 & Pa_Contig04544 & $\begin{array}{l}\text { Hypothetical protein } \\
\text { CKAN_02127100 }\end{array}$ & 11.75 \\
\hline Pa_Contig00357 & $\begin{array}{c}\text { CTP synthase-like isoform } \\
\text { X1 }\end{array}$ & 10.36 & Pa_Contig02363 & galactinol synthase 1 & 11.10 \\
\hline Pa_Contig02363 & Galactinol synthase 1 & 9.48 & Pa_Sin_HA66E9C01ARY1I & $\begin{array}{c}17.9 \mathrm{kDa} \text { class II heat-shock } \\
\text { protein-like }\end{array}$ & 10.71 \\
\hline Pa_Sin_GI32N0T02JKR74 & $\begin{array}{c}\text { ABC transporter C family } \\
\text { member } 3\end{array}$ & 9.04 & Pa_Sin_GI32N0T02IZT2Y & $\begin{array}{l}\text { Zinc finger MYM-type } \\
\text { protein 1-like protein }\end{array}$ & 10.24 \\
\hline Pa_Sin_GI32N0T02H4DYV & $\begin{array}{l}\text { DEAD-box ATP-dependent } \\
\text { RNA helicase } 56 \text { isoform X2 }\end{array}$ & 8.56 & Pa_Contig00313 & $\begin{array}{l}\text { NAC domain-containing } \\
\text { protein } 72\end{array}$ & 10.18 \\
\hline Pa_Sin_HA66E9C01B0D6Q & Redoxin & 7.93 & Pa_Sin_HA66E9C01AOOV3 & $\begin{array}{l}\text { ATP synthase subunit G } \\
\text { mitochondrial-like }\end{array}$ & 10.00 \\
\hline Pa_Sin_GI32N0T02HYARG & $\begin{array}{l}\text { Pentatricopeptide } \\
\text { repeat-containing protein } \\
\text { At5g66520 }\end{array}$ & 7.75 & Pa_Contig00357 & $\begin{array}{c}\text { CTP synthase-like isoform } \\
\text { X1 }\end{array}$ & 9.80 \\
\hline Pa_Contig03826 & $\begin{array}{l}\text { Transcription factor } \\
\text { SPATULA-like }\end{array}$ & 7.67 & Pa_Contig05359 & $\begin{array}{l}\text { Wound-responsive family } \\
\text { protein }\end{array}$ & 9.53 \\
\hline Pa_Contig06401 & $\begin{array}{l}\text { CTP synthase-like } \\
\text { Trinucleotide }\end{array}$ & 7.56 & Pa_Contig04498 & $\begin{array}{c}\text { NA } \\
\text { Pentatricopeptide }\end{array}$ & 9.48 \\
\hline Pa_Contig04336 & $\begin{array}{l}\text { repeat-containing gene } 18 \\
\text { protein }\end{array}$ & 7.15 & Pa_Sin_GI32N0T02JFLZB & $\begin{array}{l}\text { repeat-containing protein } \\
\text { At1g08070 }\end{array}$ & 8.80 \\
\hline Pa_Contig03089 & Snakin-2 & 7.07 & Pa_Contig06344 & $\begin{array}{c}\text { Serine } \\
\text { carboxypeptidase-like } 42\end{array}$ & 8.79 \\
\hline Pa_Sin_HA66E9C01ARY1I & $\begin{array}{c}17.9 \mathrm{kDa} \text { class II heat-shock } \\
\text { protein-like }\end{array}$ & 6.92 & Pa_Contig02835 & Probable nucleoredoxin 2 & 8.38 \\
\hline Pa_Sin_GI32N0T02JL4B4 & $\begin{array}{c}\text { 9-cis-epoxycarotenoid } \\
\text { dioxygenase }\end{array}$ & 6.75 & Pa_Sin_HA66E9C01AKONC & $\begin{array}{l}\text { Pyrophosphatase } \\
\text { domain-containing protein }\end{array}$ & 8.17 \\
\hline Pa_NA_RC_Contig06917 & NA & -30.10 & Pa_Sin_HA66E9C01AZE26 & $\begin{array}{c}\text { Major pollen allergen Bet } \mathrm{v} \\
\text { 1-F/I }\end{array}$ & -15.16 \\
\hline Pa_Sin_GI32N0T02JH50H & $\begin{array}{l}\text { Photosystem I P700 } \\
\text { apoprotein A1 }\end{array}$ & -19.40 & Pa_Contig07385 & $\begin{array}{c}\text { Cysteine peptidase, } \\
\text { asparagine active } \\
\text { site-containing protein }\end{array}$ & -14.04 \\
\hline
\end{tabular}


Table 3. Cont.

\begin{tabular}{|c|c|c|c|c|c|}
\hline \multicolumn{3}{|c|}{ Mild-WS } & \multicolumn{3}{|c|}{ Severe-WS } \\
\hline Name & Description & FC & Name & Description & FC \\
\hline Pa_Sin_GI32N0T02I198R & $\begin{array}{l}\text { DExH-box ATP-dependent } \\
\text { RNA helicase DExH3 }\end{array}$ & -18.78 & Pa_Contig07552 & $\begin{array}{c}\text { Peptidase_C1 } \\
\text { domain-containing } \\
\text { protein/Inhibitor_I29 }\end{array}$ & -11.27 \\
\hline Pa_Sin_HA66E9C01A762Y & $\begin{array}{l}\text { Superoxide dismutase [Mn], } \\
\text { mitochondrial }\end{array}$ & -9.61 & Pa_Sin_GI32N0T02GHCO6 & $\begin{array}{c}\text { Plasma membrane } \\
\text { ATPase } 1\end{array}$ & -11.17 \\
\hline Pa_Sin_HA66E9C01ABCHY & Protein unc-13 homolog & -8.37 & Pa_Sin_GI32N0T02I0NSB & Pyruvate decarboxylase 2 & -10.98 \\
\hline Pa_Sin_GI32N0T02IB55S & Hypothetical protein & -7.29 & Pa_Contig03628 & $\begin{array}{l}\text { Peptidoglycan-binding } \\
\text { Lysin subgroup }\end{array}$ & -10.89 \\
\hline Pa_NA_RC_Contig06574 & NA & -7.22 & Pa_Contig01574 & TIP protein & -9.40 \\
\hline Pa_Sin_HA66E9C01BUD7H & $\begin{array}{l}\text { Aspartate/other } \\
\text { aminotransferase }\end{array}$ & -6.45 & Pa_Contig02013 & Stellacyanin-like protein & -9.09 \\
\hline Pa_Sin_GI32N0T02F883Q & $\begin{array}{l}\text { Acyl-protein thioesterase, } \\
\text { putative }\end{array}$ & -6.26 & Pa_Contig00293 & Putative laccase 9 & -9.03 \\
\hline Pa_Sin_GI32N0T02J1G6J & $\begin{array}{c}\text { SusD/RagB family } \\
\text { nutrient-binding } \\
\text { lipoprotein }\end{array}$ & -5.90 & Pa_Sin_HA66E9C01AN9EE & Peroxidase 3-like & -8.82 \\
\hline Pa_NA_F_contig07053 & NA & -5.84 & Pa_Contig06873 & $\begin{array}{c}\text { Hypothetical protein } \\
\text { CKAN_01558700 } \\
\text { Putative }\end{array}$ & -8.71 \\
\hline Pa_Contig03714 & L-Idonate 5-dehydrogenase & -5.46 & Pa_Sin_GI32N0T02GK4GX & $\begin{array}{l}\text { senescence-associated } \\
\text { protein }\end{array}$ & -8.64 \\
\hline Pa_NA_RC_Contig07246 & $\begin{array}{l}\text { Hypothetical protein } \\
\text { PHALS_14482 }\end{array}$ & -5.36 & Pa_Contig05711 & $\begin{array}{c}\text { Senescence-specific cysteine } \\
\text { protease SAG39-like }\end{array}$ & -8.56 \\
\hline Pa_Contig01285 & $\begin{array}{l}\text { Pathogenesis-related } \\
\text { protein 1-like protein } \\
\text { BTB/POZ and TAZ }\end{array}$ & -5.19 & Pa_Sin_HA66E9C01BC645 & HSP20-like chaperone & -8.47 \\
\hline Pa_Contig00582 & $\begin{array}{c}\text { domain-containing protein } \\
\text { 1-like }\end{array}$ & -5.10 & Pa_Sin_GI32N0T02IPVS0 & HSP70-like protein & -8.26 \\
\hline Pa_Sin_GI32N0T02FFZXN & $\begin{array}{c}\text { Patatin/phospholipase } \\
\text { A2-related }\end{array}$ & -5.02 & Pa_Contig03714 & L-Idonate 5-dehydrogenase & -8.17 \\
\hline Pa_Sin_GI32N0T02GE7BG & Pyruvate decarboxylase 1 & -4.84 & Pa_Sin_GI32N0T02JFZ2K & $\begin{array}{c}\text { LURP1-like } \\
\text { domain-containing protein }\end{array}$ & -8.11 \\
\hline Pa_Contig06521 & $\begin{array}{l}\text { Hypothetical protein } \\
\text { VOLCADRAFT_107374 }\end{array}$ & -4.69 & Pa_Contig05100 & $\begin{array}{l}14 \mathrm{kDa} \text { proline-rich protein } \\
\text { DC2.15-like }\end{array}$ & -7.89 \\
\hline Pa_Contig01605 & $\begin{array}{l}36.4 \mathrm{kDa} \text { proline-rich } \\
\text { protein }\end{array}$ & -4.69 & Pa_Sin_GI32N0T02J1LXF & $\begin{array}{l}\text { Pentatricopeptide } \\
\text { repeat-containing protein } \\
\text { At5g18475 }\end{array}$ & -7.43 \\
\hline Pa_Contig01261 & $\begin{array}{l}\text { Basic endochitinase-like } \\
\text { protein }\end{array}$ & -4.64 & Pa_Contig05579 & $\begin{array}{l}14 \mathrm{kDa} \text { proline-rich protein } \\
\text { DC2.15-like }\end{array}$ & -7.36 \\
\hline
\end{tabular}

Regarding the molecular function (MF) subcategories, "heme binding" (GO:0020037) and "peroxidase activity" (GO:0004601) were the most represented in both mild-WS and severe-WS. The 'Dusa' rootstock response to mild-WS involved DEGs (Pa_Contig01285, Pa_Contig00894, Pa_Contig02722, Pa_Contig00544) related to deregulation of phytohormones such as abscisic acid (ABA) (Figure 5), which plays a pivotal role in drought tolerance by inducing genes involved in dehydration resistance [54-56]. Other GO terms such as "endopeptidase activity" (GO:0004252; GO:0070001) "calmodulin binding" (GO:0005516), and "water transport" (GO:0006833) were associated with severe-WS. Regarding water transport, DEGs included in this subcategory were mostly repressed aquaporins (Pa_Contig00700, Pa_Contig00807, Pa_Contig00987, Pa_Contig01574, Pa_Contig02923, Pa_Contig06862), with one of them (Pa_Contig01574) included within the top 20 repressed DEGs in severe-WS (Table 3). In this regard, the differences in $\mathrm{K}_{\mathrm{h}}$ and plant transpiration rate between mild-WS and severe-WS could be attributable to the downregulation of aquaporins in the latter since root aquaporins can contribute to $>70 \%$ of root hydraulic conductivity $[57,58]$.

Hierarchical clustering (HCL) of DEGs was performed according to the expression profiles obtained from the microarray (Figure 6). Genes were clustered into eight groups in accordance with the expression patterns observed during mild-WS and severe-WS treatments, clusters 1, 4, 5, 8 and 2, 3, 6, 7 represented contigs upregulated and downregulated, respectively. Cluster 1 was the largest group with 427 DEGs induced under 
both water shortage treatments. The most representative biological processes identified with GO term enriched analysis $(p<0.05)$ in this cluster comprised, among others, "response to water deprivation" (GO0009414), "negative regulation of endopeptidase activity" (GO0010951), "glutathione metabolic process" (GO0006749), "response to wounding" (GO0009611), "sodium ion transport" (GO0006814), and "serine-type endopeptidase inhibitor activity" (GO0004867), which have been extensively associated with both biotic and abiotic stress $[59,60]$. In particular, serine protease inhibitors play an important role in cell survival, development, and host defense, i.e., transgenic Arabidopsis thaliana plants overexpressing serine protease inhibitors showed higher RWC, reduced lipid peroxidation, and enhanced activity of antioxidant glutathione-S-transferase [61].

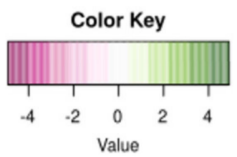

Severe-WS

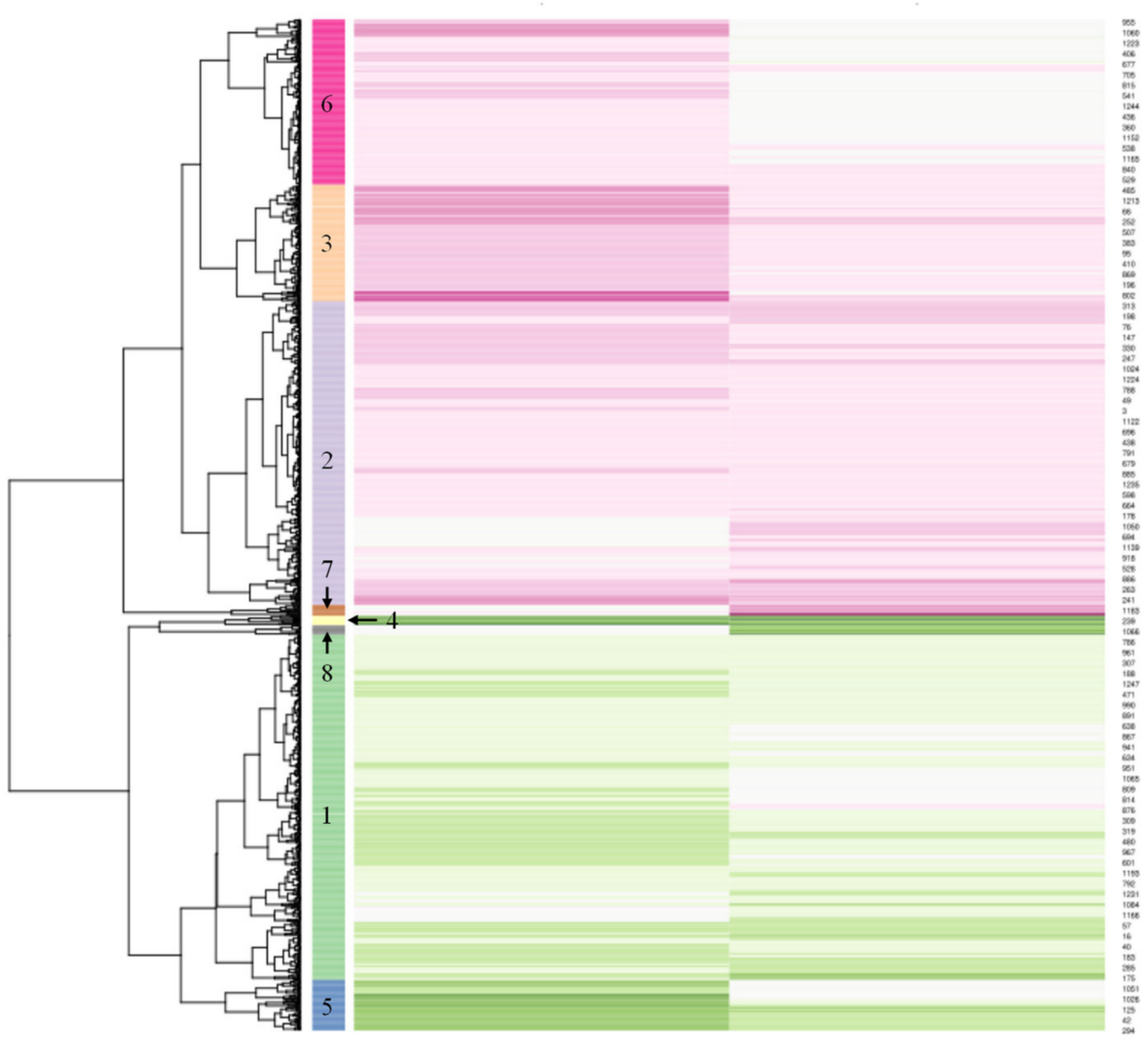

Figure 6. Hierarchical clustering (HCL) of differentially expressed genes (DEGs) in the microarray analysis of 'Dusa' avocado rootstock subjected to two different levels of water stress: mild-WS (50\% of Fc) and severe-WS (25\% of Fc).

This cluster also grouped four genes encoding the 9-cis-epoxycarotenoid dioxygenase (NCED), involved in ABA biosynthesis and related to dehydration stress tolerance in Arabidopsis [43,62-64]. Interestingly, NCED genes showed higher FC values under mildWS than in severe-WS, indicating that they are involved in the early response to water deficit. A similar expression pattern was observed for contig Pa_Contig04387 showing homology to myo-inositol-1-phoshate synthase (MIPS), which encodes a key rate-limiting enzyme involved in myo-inositol biosynthesis that plays a role in several physiological and biochemical processes such as plant immunity and hormonal regulation. Transgenic sweet potato plants overexpressing MIPS1 showed salt, drought tolerance, and stem nematode resistance, suggesting a potential use of this gene to improve resistance to biotic and abiotic stresses in plants [65]. 
Cluster 4 grouped only 12 DEGs that were strongly upregulated under both treatments. This group included key genes in the 'Dusa' response to water stress, i.e., NAC domaincontaining protein 72 (Pa_Contig00313), a transcription factor linked with drought response and known to be involved in tolerance to white root rot disease in avocado [21], genes encoding a galactinol synthase (Pa_Contig02363) associated with drought tolerance [16], and several genes encoding heat-shock proteins, reported to be involved in response to both biotic and abiotic stress [52].

Cluster 5 included 63 DEGs strongly induced in severe-WS and grouped three contigs showing homology to serine carboxipeptidases-like proteins (SCPLs) (Pa_Contig06344, Pa_Contig02982, Pa_Contig01409), which are involved in regulation of defense responses against pathogen infection and oxidative stress [66]. Moreover, their overexpression improved tolerance to drought in $A$. thaliana [67]. In contrast, cluster 8 contained 13 genes showing higher induction values in mild-WS, such as $A B C$ transporter $C$ family member (Pa_Sin_GI32N0T02JKR74), DEAD-box ATP-dependent RNA helicase 56 isoform X2 (Pa_Sin_GI32N0T02H4DYV), pentatricopeptide repeat-containing protein At5g66520 (Pa_Sin_GI32N0T02HYARG), and tetratricopeptide TPR-1 (Pa_Sin_GI32N0T02FQL49). All of them, except for Pa_Sin_GI32N0T02FQL49, were included in the top 20 genes showing higher expression in mild-WS. Both $\mathrm{ABC}$ transporters and tetratricopeptide-repeat proteins are involved in ABA signaling pathways and, therefore, in the activation of genes that improve drought stress tolerance [68-70].

Among clusters grouping repressed contigs, Cluster 2 and 3 collected contigs that were downregulated under both water treatments; cluster 3 was the largest one with 376 DEGs of which 13 of them were represented in the top 20 list of downregulated contigs (Table 3). Cluster 2 included four pathogenesis-related protein PR-4 (Pa_Contig06278, Pa_Contig07140, Pa_Contig05982, Pa_Contig07403) and four endochitinases (Pa_Contig01261, Pa_Contig01395, Pa_Contig07157, Pa_Contig06246), previously reported to be induced by the jasmonic acid (JA) pathway known to be inhibited in response to water deprivation [71].

The remaining downregulated contigs were grouped into clusters 6 and 7; cluster 6 grouped those repressed in severe-WS and not affected in mild-WS, while cluster 7 brought together those repressed under mild-WS and not affected under severe-WS.

\subsection{Modeling 'Dusa' Response to Different Levels of Water Stress: Linking Plant Physiology with the Root-Induced Drought-Tolerant Genes}

Plants have evolved different adaptive mechanisms to cope with water scarcity at multiple stages ranging from the molecular to whole-plant physiological level. Taking together the physiological and molecular results presented in this study, a schematic model for 'Dusa' rootstock in response to soil water depletion is proposed (Figure 7). At the leaf level, drought stress in 'Dusa' rootstock triggered water losses, lowering water potential and reducing photosynthesis, probably linked to the tight modulation of stomatal closure by ABA, which is consistent with the overexpression of genes involved in ABA biosynthetic and signaling pathways observed under both treatments in the roots.

In addition to phytohormones, numerous families of transcription factors (TF), such as NAC, MYB, and WRKY are known to be involved in signaling events associated with water stress in plants [72], playing a significant role in drought tolerance [73]. Our analysis identified $15 \mathrm{TF}$ related to drought tolerance that were induced under both mild-WS and severe-WS treatments. Among them, there were five NAC domain-containing proteins, as well as four MYB and three WRKY TFs (Table 4). MYB TFs constitute one of the largest families that coordinate plant defense responses to various stresses, phytohormone signaling, and various metabolic processes [74]. Some MYB and NAC TFs have been related to lateral root growth under drought $[17,19,75-77]$, which is consistent with the early increment in root biomass observed in mild-WS and severe-WS plants. 


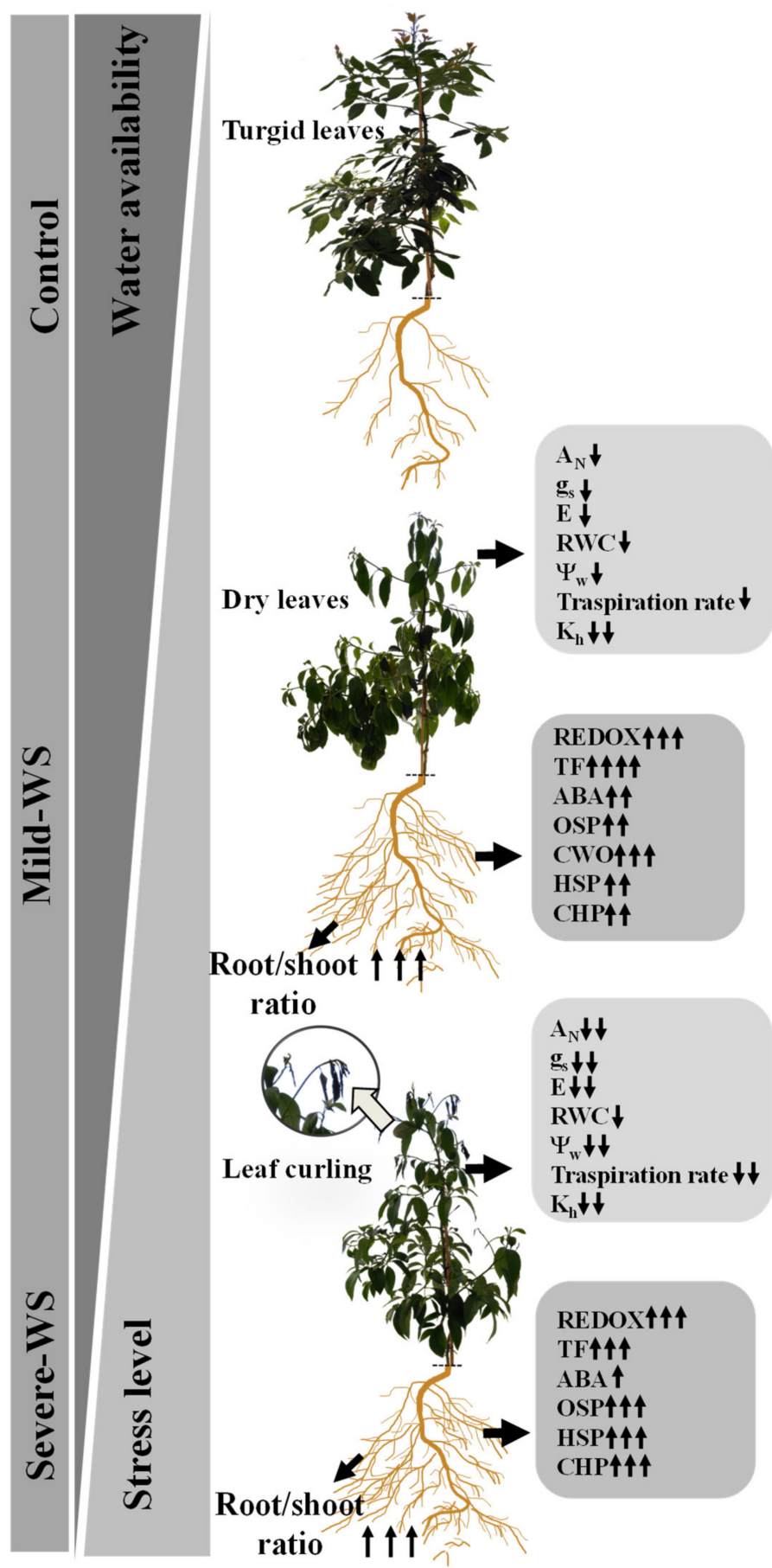

Figure 7. Comparative response of 'Dusa' avocado rootstock subjected to two different levels of water stress: mild-WS ( $50 \%$ of $\mathrm{Fc}$ ) and severe-WS ( $25 \%$ of $\mathrm{Fc}$ ). Physiological response to the different levels of water stress are represented with changes in net $\mathrm{CO}_{2}$ assimilation rate $\left(A_{\mathrm{N}}\right)$, stomatal conductance $\left(g_{\mathrm{s}}\right)$, transpiration rate $(\mathrm{E})$, relative water content $(\mathrm{RWC})$, leaf water potential $\left(\Psi_{\mathrm{w}}\right)$, plant transpiration rate, and plant hydraulic conductance $\left(\mathrm{K}_{\mathrm{h}}\right)$. At a molecular level, mild and severe-WS treatment trigger the overexpression of genes encoding detoxification enzymes (REDOX), transcription factors (TFs), abscisic acid pathway (ABA), osmoprotectants (OSP), cell-wall organization (CWO), heat-shock proteins (HSPs), and chaperones (CHPs). 
Table 4. Water stress-related differentially expressed genes (DEGs) from 'Dusa' avocado rootstocks subjected to two different levels of water stress: mild-WS ( $50 \%$ of $\mathrm{Fc}$ ) and severe-WS ( $25 \%$ of $\mathrm{Fc}$ ) (FC, fold change).

\begin{tabular}{|c|c|c|c|c|c|}
\hline Sequence name & Description & Function & $\begin{array}{l}\text { Mild-WS } \\
\text { FC }\end{array}$ & $\begin{array}{l}\text { Severe-WS } \\
\text { FC }\end{array}$ & References \\
\hline \multicolumn{6}{|c|}{ Transcription factor } \\
\hline Pa_Contig00978 & B-box zinc finger protein 32 & Transcription factor & 2.50 & 2.73 & [78-80] \\
\hline Pa_Contig00204 & $\begin{array}{c}\text { Zinc finger CCCH } \\
\text { domain-containing protein } 20\end{array}$ & Transcription factor & 2.54 & 2.66 & [78-80] \\
\hline Pa_Contig04595 & Zinc finger protein ZAT10 & Transcription factor & 2.45 & 2.85 & [78-80] \\
\hline Pa_Sin_GI32N0T02FVARP & $\begin{array}{l}\text { Heat stress transcription factor } \\
\qquad \mathrm{B}-2 \mathrm{a}\end{array}$ & Transcription factor & 3.33 & & [81] \\
\hline Pa_Sin_GI32N0T02J04TC & $\begin{array}{l}\text { Heat stress transcription factor } \\
\text { B-3 }\end{array}$ & Transcription factor & 2.44 & 3.13 & {$[81]$} \\
\hline Pa_Sin_GI32N0T02GJ71A & $\begin{array}{l}\text { Heat stress transcription factor } \\
\text { C-1 }\end{array}$ & Transcription factor & 4.41 & 5.44 & {$[81]$} \\
\hline Pa_Contig00660 & $\begin{array}{l}\text { Homeobox-leucine zipper protein } \\
\text { HAT5 }\end{array}$ & Transcription factor & 4.51 & 2.32 & [82] \\
\hline Pa_Contig01191 & NAC domain-containing protein 2 & Transcription factor & 3.88 & 4.15 & [83-87] \\
\hline Pa_Contig03450 & NAC domain-containing protein 2 & Transcription factor & 3.67 & 5.30 & [83-87] \\
\hline Pa_Contig00313 & $\begin{array}{l}\text { NAC domain-containing } \\
\text { protein } 72\end{array}$ & Transcription factor & 12.71 & 10.18 & {$[83-87]$} \\
\hline Pa_Contig07055 & $\begin{array}{l}\text { NAC domain-containing protein } \\
\text { 82-like protein }\end{array}$ & Transcription factor & 1.88 & 2.60 & {$[83-87]$} \\
\hline Pa_Contig07561 & $\begin{array}{l}\text { NAC domain-containing protein } \\
\text { 82-like protein }\end{array}$ & Transcription factor & 1.94 & 2.57 & [83-87] \\
\hline Pa_Contig03801 & $\begin{array}{c}\text { Probable WRKY transcription } \\
\text { factor } 31\end{array}$ & Transcription factor & & 2.05 & {$[88]$} \\
\hline Pa_Contig04109 & $\begin{array}{c}\text { Probable WRKY transcription } \\
\text { factor } 48\end{array}$ & Transcription factor & 1.33 & 2.48 & {$[88]$} \\
\hline Pa_Contig03985 & Transcription factor MYB1R1 & $\begin{array}{l}\text { Transcription factor } \\
\text { Transcription factor, }\end{array}$ & 2.15 & 2.64 & {$[89]$} \\
\hline Pa_Contig05714 & Transcription factor MYBS3 & $\begin{array}{l}\text { Response to } \\
\text { hormones }\end{array}$ & 2.06 & 1.99 & {$[89]$} \\
\hline Pa_Contig05191 & Trihelix transcription factor ASIL2 & Transcription factor & 1.69 & 2.36 & [90-92] \\
\hline \multicolumn{6}{|c|}{ Hormonal regulation } \\
\hline Pa_Sin_GI32N0T02JL4B4 & $\begin{array}{l}\text { 9-cis-Epoxycarotenoid } \\
\text { dioxygenase }\end{array}$ & $\begin{array}{c}\text { Abscisic acid } \\
\text { signaling pathway }\end{array}$ & 6.75 & 2.34 & {$[62,63,93-95]$} \\
\hline Pa_Sin_GI32N0T02HK1RI & $\begin{array}{l}\text { 9-cis-Epoxycarotenoid } \\
\text { dioxygenase NCED1 }\end{array}$ & $\begin{array}{l}\text { Abscisic acid } \\
\text { signaling pathway }\end{array}$ & 5.71 & 1.55 & {$[62,63,93-95]$} \\
\hline Pa_Sin_HA66E9C01AOCH8 & $\begin{array}{c}\text { Putative 9-cis-epoxycarotenoid } \\
\text { dioxygenase }\end{array}$ & $\begin{array}{l}\text { Abscisic acid } \\
\text { signaling pathway }\end{array}$ & 4.29 & 1.70 & {$[62,63,93-95]$} \\
\hline Pa_Contig04541 & $\begin{array}{l}\text { Abscisic acid-insensitive 5-like } \\
\text { protein } 5\end{array}$ & $\begin{array}{l}\text { Abscisic acid } \\
\text { signaling pathway }\end{array}$ & 2.30 & 1.70 & {$[96,97]$} \\
\hline Pa_Contig01488 & $\begin{array}{l}\text { Probable protein phosphatase } \\
\qquad 2 \mathrm{C} 24\end{array}$ & $\begin{array}{l}\text { Abscisic acid } \\
\text { signaling pathway }\end{array}$ & 4.19 & 2.12 & {$[98,99]$} \\
\hline Pa_Contig04387 & $\begin{array}{l}\text { Myo-inositol-1-phosphate } \\
\text { synthase }\end{array}$ & Stress signaling & 5.97 & 3.80 & {$[100-103]$} \\
\hline \multicolumn{6}{|c|}{ Redox homeostasis } \\
\hline Pa_Contig00910 & Ubiquinol oxidase 2 & $\begin{array}{l}\text { Alternative oxidase } \\
\text { (AOX) activity }\end{array}$ & 2.52 & 3.78 & {$[104]$} \\
\hline Pa_Contig02586 & Glutathione S-transferase 23-like & $\begin{array}{l}\text { Glutathione } \\
\text { transferase activity }\end{array}$ & 2.32 & 3.50 & {$[105-107]$} \\
\hline Pa_Contig05480 & $\begin{array}{l}\text { Probable glutathione } \\
\text { S-transferase }\end{array}$ & $\begin{array}{l}\text { Glutathione } \\
\text { transferase activity }\end{array}$ & 2.14 & 1.88 & {$[105-107]$} \\
\hline Pa_Contig01550 & $\begin{array}{l}\text { Probable glutathione } \\
\text { S-transferase parA }\end{array}$ & $\begin{array}{l}\text { Glutathione } \\
\text { transferase activity }\end{array}$ & 2.14 & 1.42 & {$[105-107]$} \\
\hline Pa_Contig01827 & Putative glutathione $S$-transferase & $\begin{array}{l}\text { Glutathione } \\
\text { transferase activity }\end{array}$ & 4.40 & 2.62 & {$[105-107]$} \\
\hline Pa_Contig02245 & $\begin{array}{l}\text { Alcohol dehydrogenase } \\
\text { superfamily, zinc-type }\end{array}$ & $\begin{array}{l}\text { Oxidoreductase } \\
\text { activity }\end{array}$ & 2.01 & 2.26 & {$[108]$} \\
\hline Pa_Sin_GI32N0T02JXR49 & Amine oxidase & $\begin{array}{l}\text { Oxidoreductase } \\
\text { activity }\end{array}$ & 2.13 & 2.12 & {$[109,110]$} \\
\hline Pa_Sin_HA66E9C01AHBP7 & Amine oxidase & $\begin{array}{l}\text { Oxidoreductase } \\
\text { activity }\end{array}$ & 2.09 & 2.37 & {$[109,110]$} \\
\hline Pa_Sin_GI32N0T02HAOKJ & $\begin{array}{c}\text { Cytokinin dehydrogenase } 7 \\
\text { isoform } \mathrm{X} 2\end{array}$ & $\begin{array}{l}\text { Oxidoreductase } \\
\text { activity }\end{array}$ & 2.04 & & {$[111-113]$} \\
\hline Pa_Sin_GI32N0T02H5ZVO & Lipoxygenase 6 & $\begin{array}{l}\text { Oxidoreductase } \\
\text { activity }\end{array}$ & & 2.04 & {$[114-116]$} \\
\hline
\end{tabular}


Table 4. Cont

\begin{tabular}{|c|c|c|c|c|c|}
\hline Sequence name & Description & Function & $\begin{array}{l}\text { Mild-WS } \\
\text { FC }\end{array}$ & $\begin{array}{l}\text { Severe-WS } \\
\text { FC }\end{array}$ & References \\
\hline \multicolumn{6}{|c|}{ Transcription factor } \\
\hline Pa_Contig01521 & $\begin{array}{c}\text { NADP-dependent } \\
\text { glyceraldehyde-3-phosphate } \\
\text { dehydrogenase }\end{array}$ & $\begin{array}{l}\text { Oxidoreductase } \\
\text { activity }\end{array}$ & 2.44 & 2.03 & {$[117,118]$} \\
\hline Pa_Sin_GI32N0T02IWQT9 & $\begin{array}{l}\text { Probable cinnamyl alcohol } \\
\text { dehydrogenase } 6\end{array}$ & $\begin{array}{l}\text { Oxidoreductase } \\
\text { activity, lignin } \\
\text { biosynthesis }\end{array}$ & & 2.68 & [119-121] \\
\hline Pa_Contig04086 & Sorbitol dehydrogenase & $\begin{array}{l}\text { Oxidoreductase } \\
\text { activity }\end{array}$ & 3.03 & 3.47 & {$[122,123]$} \\
\hline Pa_Contig03274 & Thioredoxin-like protein CXXS1 & $\begin{array}{l}\text { Oxidoreductase } \\
\text { activity }\end{array}$ & & 2.17 & {$[124,125]$} \\
\hline Pa_Contig01894 & $\begin{array}{l}\text { Corytuberine synthase } \\
\text { (Cytochrome P450) }\end{array}$ & $\begin{array}{l}\text { Oxidoreductase } \\
\text { activity }\end{array}$ & 2.28 & 1.35 & [126-128] \\
\hline Pa_Contig01546 & $\begin{array}{c}\text { Cytochrome P450 } \\
\text { CYP72A219-like protein }\end{array}$ & $\begin{array}{l}\text { Oxidoreductase } \\
\text { activity }\end{array}$ & 1.71 & 2.07 & [126-128] \\
\hline Pa_Contig01573 & Cytochrome P450 714C2-like & $\begin{array}{l}\text { Oxidoreductase } \\
\text { activity }\end{array}$ & 3.88 & 3.22 & [126-128] \\
\hline Pa_Contig01652 & Cytochrome P450 71A1 & $\begin{array}{l}\text { Oxidoreductase } \\
\text { activity }\end{array}$ & 2.37 & 3.52 & [126-128] \\
\hline Pa_Contig07139 & Cytochrome P450 71A1 & $\begin{array}{l}\text { Oxidoreductase } \\
\text { activity }\end{array}$ & 2.34 & 3.11 & [126-128] \\
\hline Pa_Contig07325 & Cytochrome P450 71A1 & $\begin{array}{l}\text { Oxidoreductase } \\
\text { activity }\end{array}$ & 2.04 & 3.00 & [126-128] \\
\hline Pa_Contig07667 & Cytochrome P450 71A1 & $\begin{array}{l}\text { Oxidoreductase } \\
\text { activity }\end{array}$ & 2.36 & 3.16 & [126-128] \\
\hline Pa_Contig00616 & Cytochrome P450 89A2 & $\begin{array}{l}\text { Oxidoreductase } \\
\text { activity }\end{array}$ & 3.03 & 2.80 & [126-128] \\
\hline Pa_Contig04644 & Cytochrome P450 89A2 & $\begin{array}{l}\text { Oxidoreductase } \\
\text { activity }\end{array}$ & 5.79 & 3.53 & [126-128] \\
\hline Pa_Sin_HA66E9C01B0D6Q & 1-Cys peroxiredoxin isozyme & Peroxidase activity & 7.93 & & [129] \\
\hline Pa_Sin_GI32N0T02JBZZB & Peroxiredoxin Q & Peroxidase activity & & 2.25 & [129] \\
\hline Pa_Contig05152 & Cationic peroxidase 1-like & Peroxidase activity & 2.01 & & [130-132] \\
\hline Pa_Contig06649 & Cationic peroxidase 1-like & Peroxidase activity & 2.13 & 5.48 & [130-132] \\
\hline Pa_Contig04553 & Peroxidase 12-like & Peroxidase activity & & 2.01 & [130-132] \\
\hline \multicolumn{6}{|c|}{ Protease and protease inhibitor activity } \\
\hline Pa_Contig01409 & Serine carboxypeptidase-like 42 & $\begin{array}{l}\text { Intracellular turnover } \\
\text { of proteins }\end{array}$ & 2.69 & 5.98 & {$[67,133]$} \\
\hline Pa_Contig02982 & Serine carboxypeptidase-like 42 & $\begin{array}{l}\text { Intracellular turnover } \\
\text { of proteins }\end{array}$ & 1.87 & 6.32 & {$[67,133]$} \\
\hline Pa_Contig06344 & Serine carboxypeptidase-like 42 & $\begin{array}{l}\text { Intracellular turnover } \\
\text { of proteins }\end{array}$ & 2.19 & 8.79 & {$[67,133]$} \\
\hline Pa_Contig03889 & Desumoylating isopeptidase 1 & $\begin{array}{l}\text { Post-translational } \\
\text { mechanism in } \\
\text { respond to stress }\end{array}$ & 1.71 & 2.02 & [134] \\
\hline Pa_Contig02540 & Kunitz trypsin inhibitor 2 & $\begin{array}{l}\text { Protease inhibitor, } \\
\text { wound and } \\
\text { herbivores response }\end{array}$ & 1.40 & 2.10 & [59] \\
\hline Pa_Contig00984 & $\begin{array}{l}\text { Cysteine proteinase inhibitor } \\
\text { 12-like }\end{array}$ & Proteinase inhibitor & 1.94 & 2.36 & {$[49,61,135,136]$} \\
\hline Pa_Contig05072 & Proteinase inhibitor & Proteinase inhibitor & 1.44 & 2.47 & {$[49,61,135,136]$} \\
\hline Pa_NA_RC_Contig07158 & Proteinase inhibitor I3 & Proteinase inhibitor & 1.42 & 3.05 & {$[49,61,135,136]$} \\
\hline Pa_Contig03565 & Subtilisin-like protease SBT3.17 & $\begin{array}{l}\text { Serine protease, plant } \\
\text { defense response }\end{array}$ & & 2.68 & {$[137,138]$} \\
\hline \multicolumn{6}{|c|}{ Chaperone and heat shock proteins } \\
\hline Pa_Contig03398 & Chaperone protein ClpB1 & Chaperone activity & 3.33 & 4.30 & [139] \\
\hline Pa_Sin_GI32N0T02HS82J & Chaperone protein ClpB1 & Chaperone activity & 3.56 & 5.20 & [139] \\
\hline Pa_Sin_GI32N0T02HS9YT & Chaperone protein ClpB1 & Chaperone activity & 3.70 & 6.05 & [139] \\
\hline Pa_Contig03328 & Chaperone protein dnaJ 11 & Chaperone activity & 2.47 & 2.68 & [139] \\
\hline Pa_Sin_HA66E9C01AV9KD & Chaperonin-like RbcX protein 2 & Chaperone activity & 2.86 & 3.94 & [139] \\
\hline Pa_Sin_GI32N0T02GU01I & Chaperonin-like RbcX protein 2 & Chaperone activity & & 3.65 & [139] \\
\hline Pa_Sin_HA66E9C01BZUZG & $\begin{array}{c}15.7 \mathrm{kDa} \text { heat-shock protein, } \\
\text { peroxisomal }\end{array}$ & $\begin{array}{l}\text { Heat-shock protein } \\
\text { activity }\end{array}$ & 2.12 & 3.43 & [139] \\
\hline Pa_Sin_HA66E9C01AHKXT & $\begin{array}{l}17.3 \mathrm{kDa} \text { class II heat-shock } \\
\text { protein }\end{array}$ & $\begin{array}{l}\text { Heat-shock protein } \\
\text { activity }\end{array}$ & 5.67 & 5.93 & [139] \\
\hline Pa_Contig01858 & $\begin{array}{l}17.8 \mathrm{kDa} \text { class I heat-shock } \\
\text { protein-like }\end{array}$ & $\begin{array}{l}\text { Heat-shock protein } \\
\text { activity }\end{array}$ & 3.94 & 5.70 & [139] \\
\hline
\end{tabular}


Table 4. Cont.

\begin{tabular}{|c|c|c|c|c|c|}
\hline Sequence name & Description & Function & $\begin{array}{l}\text { Mild-WS } \\
\text { FC }\end{array}$ & $\begin{array}{l}\text { Severe-WS } \\
\text { FC }\end{array}$ & References \\
\hline \multicolumn{6}{|c|}{ Transcription factor } \\
\hline Pa_Sin_HA66E9C01ARY1I & $\begin{array}{l}17.9 \mathrm{kDa} \text { class II heat-shock } \\
\text { protein-like }\end{array}$ & $\begin{array}{l}\text { Heat-shock protein } \\
\text { activity }\end{array}$ & 6.92 & 10.71 & [139] \\
\hline Pa_Sin_FZ03KKT01BNH1K & $\begin{array}{l}18.1 \text { kDa class I heat-shock } \\
\text { protein-like }\end{array}$ & $\begin{array}{l}\text { Heat-shock protein } \\
\text { activity }\end{array}$ & 28.94 & 23.07 & [139] \\
\hline Pa_Sin_HA66E9C01AIWJ3 & $25.3 \mathrm{kDa}$ heat-shock protein & $\begin{array}{l}\text { Heat-shock protein } \\
\text { activity }\end{array}$ & 6.14 & 12.05 & [139] \\
\hline Pa_Contig02550 & Class I heat-shock-like protein & $\begin{array}{l}\text { Heat-shock protein } \\
\text { activity }\end{array}$ & 3.23 & 5.38 & [139] \\
\hline Pa_Sin_GI32N0T02I40L4 & Class I heat-shock-like protein & $\begin{array}{l}\text { Heat-shock protein } \\
\text { activity }\end{array}$ & 1.54 & 3.31 & [139] \\
\hline Pa_Sin_HA66E9C01AFKWO & Heat-shock $70 \mathrm{kDa}$ protein & $\begin{array}{l}\text { Heat-shock protein } \\
\text { activity }\end{array}$ & & 3.60 & [139] \\
\hline Pa_Sin_GI32N0T02GPO75 & Heat-shock $70 \mathrm{kDa}$ protein 15 -like & $\begin{array}{l}\text { Heat-shock protein } \\
\text { activity }\end{array}$ & 4.71 & & [139] \\
\hline Pa_Sin_GI32N0T02J33GV & Heat-shock 70 kDa protein 17 & $\begin{array}{l}\text { Heat-shock protein } \\
\text { activity }\end{array}$ & 3.30 & & [139] \\
\hline Pa_Contig00041 & $\begin{array}{l}\text { Heat-shock cognate } 70 \mathrm{kDa} \\
\text { protein } 2\end{array}$ & $\begin{array}{l}\text { Heat-shock protein } \\
\text { activity }\end{array}$ & 1.64 & 2.02 & [139] \\
\hline Pa_Sin_GI32N0T02FE65Z & Heat-shock protein & $\begin{array}{l}\text { Heat-shock protein } \\
\text { activity }\end{array}$ & 3.59 & 5.30 & [139] \\
\hline Pa_Contig04262 & Heat-shock protein 70 & $\begin{array}{l}\text { Heat-shock protein } \\
\text { activity }\end{array}$ & 2.05 & 2.63 & [139] \\
\hline Pa_Contig00058 & Heat-shock protein 83 & $\begin{array}{l}\text { Heat-shock protein } \\
\text { activity }\end{array}$ & 3.74 & 4.25 & [139] \\
\hline Pa_Contig05589 & Small heat-shock protein & $\begin{array}{l}\text { Heat-shock protein } \\
\text { activity }\end{array}$ & 1.82 & 2.40 & [139] \\
\hline \multicolumn{6}{|c|}{ Osmoprotectant } \\
\hline Pa_Contig02363 & Galactinol synthase 1 & $\begin{array}{l}\text { Galactose } \\
\text { metabolism }\end{array}$ & 9.48 & 11.10 & [140-142] \\
\hline Pa_Contig04773 & Galactinol synthase 1-like & $\begin{array}{l}\text { Galactose } \\
\text { metabolism }\end{array}$ & 5.25 & 6.49 & [140-142] \\
\hline Pa_Contig00418 & $\begin{array}{l}\text { Probable galactinol-sucrose } \\
\text { galactosyltransferase } 2\end{array}$ & $\begin{array}{l}\text { Myo-inositol and } \\
\text { raffinose synthesis }\end{array}$ & 2.15 & 2.83 & [100-103] \\
\hline Pa_Contig02227 & $\begin{array}{l}\text { Probable galactinol-sucrose } \\
\text { galactosyltransferase } 2\end{array}$ & $\begin{array}{l}\text { Myo-inositol and } \\
\text { raffinose synthesis }\end{array}$ & 2.14 & 2.30 & [100-103] \\
\hline Pa_Sin_GI32N0T02GAY0V & Proline transporter 2-like & $\begin{array}{l}\text { Proline metabolic } \\
\text { process }\end{array}$ & 2.65 & 3.14 & [143-145] \\
\hline Pa_Contig05170 & $\begin{array}{l}\text { Beta-fructofuranosidase, soluble } \\
\text { isoenzyme I-like }\end{array}$ & $\begin{array}{l}\text { Sucrose metabolic } \\
\text { process }\end{array}$ & 4.03 & 5.32 & [146] \\
\hline \multicolumn{6}{|c|}{ Cell-wall organization } \\
\hline Pa_Contig05067 & Expansin-like A2 & $\begin{array}{c}\text { Cell-wall } \\
\text { organization }\end{array}$ & 2.41 & 1.55 & {$[147,148]$} \\
\hline Pa_Contig00733 & $\begin{array}{c}\text { Probable xyloglucan } \\
\text { endotransglucosylase/hydrolase } \\
\text { protein } 23\end{array}$ & $\begin{array}{l}\text { Cell-wall } \\
\text { organization }\end{array}$ & 4.64 & 5.16 & [149-151] \\
\hline Pa_Contig01176 & $\begin{array}{c}\text { Probable xyloglucan } \\
\text { endotransglucosylase/hydrolase } \\
\text { protein } 27\end{array}$ & $\begin{array}{c}\text { Cell-wall } \\
\text { organization }\end{array}$ & 2.14 & 1.86 & [149-151] \\
\hline
\end{tabular}

Despite the stomatal limitations of photosynthesis, the severity of the imposed stress in this study was counteracted by the induction of genes related to redox homeostasis such as those encoding peroxidases, cytochrome P450, glutathione transferases, and alterative oxidase enzymes (AOX), among others (Table 4), helping to prevent damage development and cell death as reported in previous studies [105,106,126-132]. In addition, a total of 18 chaperones and heat-shock proteins (HSPs) with chaperone function, probably preventing protein aggregation and denaturation during oxidative stress, were induced under both treatments, reaching higher values in severe-WS. HSPs with chaperone function included different classes such as HSP70 and HSPs below $30 \mathrm{kDa}$, all of them known to be induced in drought-tolerant plants under drought stress [139]. 
Increased drought stress intensity was not reflected in further decreases in RWC, which showed similar values under both water treatments; this could be related to the overexpression of genes involved in osmotic adjustment at the root level such as those encoding the galactinol synthase 1, galactinol-sucrose galactosyltransferase, and proline transporter (Table 4) [152,153]. This would enable water uptake and maintaining cell turgor under low water availability. In this sense, the upregulation of genes encoding xyloglucan endo- $\beta$-transglucosylases/hydrolases and expansins observed in 'Dusa' rootstocks after water stress (Table 4) could be linked to maintenance of cell-wall plasticity and prevention of cell turgor loss [154]. The implication of xyloglycan biosynthesis-related enzymes and expansins with drought tolerance is well documented [147-151].

The involvement of proteinases and proteinase inhibitor enzymes in the 'Dusa' response to soil water deprivation was reflected by the induction of genes encoding four serine proteases, a desumoylating isopeptidase 1 (Table 4), and four protease inhibitors. Their expression was linked to the stress severity, reaching the gene encoding a serine carboxypeptidase-like 42 with a fold-change value of 8.79 under severe-WS. Serine peptidases have been recently implicated in orchestrating the stomatal response to abiotic and biotic factors leading to enhanced water use efficiency and, therefore, drought tolerance [155]. In relation to the protease inhibitors, they have been reported to play an important role in several biological processes such as mobilization of storage proteins, regulation of endogenous enzymatic activities, modulation of apoptosis, and programmed cell death [60]. In transgenic plants, the overexpression of protease inhibitors has been associated with enhanced abiotic stress tolerance, such as water stress [49]. In addition, avocado tolerance to Rosellinia necatrix has been previously linked to the upregulation of protease inhibitors [21], suggesting a possible role of these proteins in the response to both biotic and abiotic stresses.

\section{Conclusions}

This study contributes to understanding the molecular mechanisms associated with drought stress response in 'Dusa' avocado rootstock. The microarray analysis revealed the overexpression of genes related to traits that could contribute to drought tolerance, including those involved in ABA biosynthesis, synthesis of osmoprotectants, activation of antioxidant defense, and systems repair, among others. Some of these genes have been linked to tolerance to certain biotic factors, such as fungal invasion, supporting the fact that plant responses against biotic and abiotic stress are based on common mechanisms. The molecular response, together with the ability of stressed plants to restore their physiological performance immediately after water replenishment, highlights that 'Dusa' avocado rootstock shows a certain degree of tolerance to water stress. Although future field trials need to be carried out using grafted plants in commercial orchards, results presented here open the possibility of using deficit irrigation as a strategy for water saving in cropping areas with limited water resources, such as the Andalusia Coast of Spain; moreover, taking into account the important role of water availability in growth of soil-borne pathogens, this water shortage could be a useful tool in soil-disease management.

\section{Materials and Methods}

\subsection{Plant Material and Experimental Design}

The study was carried out at the Institute of Agricultural Research and Training (IFAPA) (Málaga, southeastern Spain, $36^{\circ} 40^{\prime} 25^{\prime \prime} \mathrm{N}, 04^{\circ} 30^{\prime} 11^{\prime \prime} \mathrm{W}, 32 \mathrm{~m}$ below sea level) with 352 year old clonal 'Dusa' plants (Westfalia Estate, South Africa). Avocado plants were propagated by the Brokaw nursery (Brokaw España S.L.) using a modified Frohlich method [156] and grown in $28 \mathrm{~L}$ pots containing a sterilized mixture of organic substrate and sand supplemented with a slow-release fertilizer (Basacote Plus 6M, Compo Expert, Castellón, Spain). Prior to the experiment, plants were irrigated according to their needs to ensure soil wetness, and pots were covered with a black plastic to avoid soil evaporation. 
Once per week, plants were fertilized with an NPK solution (Kristalon Blue 17-6-18, Yara, Oslo, Norway) supplemented with iron chelate (Sequestrene ${ }^{\circledR}$, Syngenta, Madrid, Spain).

The experimental design is depicted in Figure 1. Nine plants were randomly assigned to the control, in which soil moisture was maintained at field capacity $(\mathrm{Fc})$ throughout the experimentation, and 26 plants were subjected to controlled substrate drying-up until they reached $50 \%$ of $\mathrm{Fc}$ (i.e., mild water stress, mild-WS). At this point, irrigation was restored in nine avocado plants for assessing their drought recovery response, whereas 13 plants were further desiccated until soil moisture reached $25 \%$ of $\mathrm{Fc}_{\mathrm{c}}$ (i.e., severe water stress, severe-WS), which were subsequently rewatered until their initial water status was recovered (Figure $2 \mathrm{~A}$ ).

Soil moisture was measured daily in all plants using a wet sensor (HH2 Moisture meter, Delta-T Devices. Cambridge, England). The sensor was previously calibrated for the substrate, allowing the adjustment of volumetric soil moisture $(v / v)$ on each water treatment (mild-WS and severe-WS) in relation to the soil water holding at field capacity (Fc $\sim 0.4 v / v$ ). The experiment was conducted in a greenhouse under daylight illumination and semi-controlled conditions of air temperature (T) and relative humidity (RH). Photosynthetic photon flux density (PPFD), $\mathrm{T}$, and RH conditions inside the greenhouse were continuously registered by a quantum sensor (Apogee SQ-110, UT, USA) and by a T/RH U23-001 HOBO ${ }^{\circledR}$ Pro v2 logger (Onset Computer Corporation, MA, USA). Maximal midday values of PPFD varied between 701 and $1051 \mu \mathrm{mol} \cdot \mathrm{m}^{-2} \cdot \mathrm{s}^{-1}$, and daily T fluctuated according to external weather conditions, but its variation range inside the greenhouse was maintained between $20 \pm 5{ }^{\circ} \mathrm{C}$ by an automatic cooling system and heating when necessary. The RH values inside the greenhouse were always over $33 \%$.

Throughout the experiment, physiological measurements and root samplings were carried out at $t_{1}, t_{2}$, and $t_{3}$. Biomass partitioning was measured in four plants from each water treatment.

\subsection{Physiological Measurements}

Predawn (05:00-06:00 a.m.) and midday (12:00-1:00 p.m.) leaf water potential was measured using a Schölander pressure chamber (model 3005; Soil Moisture Equipment Corporation, Santa Barbara, CA, USA). On each plant, one mature fully developed leaf per plant close to the main stem was measured following the recommendations made by Hsiao [157]. Maximal photochemical efficiency of PSII $(F \mathrm{v} / F \mathrm{~m})$ was also measured at predawn using a Pulse Amplitude Modulation (PAM-2000) fluorometer (Heinz Walz $\mathrm{GmbH}$, Effeltrich, Germany). Relative leaf water content (RWC), the specific leaf mass area (LMA), and relative chlorophyll content (SPAD index) were measured only at $t_{1}$ in the same plants as for leaf water potential. For RWC determinations, leaf discs $\left(2 \mathrm{~cm}^{2}\right)$ were taken at midday and weighed to obtain fresh weight $\left(\mathrm{F}_{\mathrm{W}}\right)$, before being immediately imbibed on distilled water for $24 \mathrm{~h}$ at $5{ }^{\circ} \mathrm{C}$ in darkness for obtaining turgid weight $\left(\mathrm{T}_{\mathrm{W}}\right)$. Afterward, samples were oven-dried at $80{ }^{\circ} \mathrm{C}$ for $48 \mathrm{~h}$ to get dry weight $\left(\mathrm{D}_{\mathrm{W}}\right)$. RWC was calculated as follows:

$$
\operatorname{RWC}(\%)=\left(\left(F_{W}-D_{W}\right) /\left(T_{W}-D_{W}\right)\right) \times 100 .
$$

The specific LMA was calculated as the ratio between disc Dw and disc area $\left(\mathrm{g} \cdot \mathrm{cm}^{-2}\right)$. LMA values were used to translate leaf dry biomass into plant foliar area. Leaf gas exchange was measured in one mature exposed leaf per plant at midday (11:00 a.m.-2:00 p.m.) at $t_{1}$ and $t_{2}$. Measurements were done with an open portable photosynthesis system (model LI-6400, LI-COR, NE, USA) equipped with an LED light source (6400-02B) coupled to a sensor head/IRGA, and with a $\mathrm{CO}_{2}$ mixer (6400-01). Settings for measurements were as follows: flow rate, $500 \mathrm{~mL} \cdot \mathrm{min}^{-1} ; \mathrm{CO}_{2}$ partial pressure, $400 \mathrm{ppm}$; photosynthetic photon flux density, $1000 \mu \mathrm{mol} \cdot \mathrm{m}^{-2} \cdot \mathrm{s}^{-1}$; leaf temperature, $\sim 20^{\circ} \mathrm{C}$; relative humidity, $\sim 50 \%$ (vapor pressure deficit $\sim 1.4 \mathrm{kPa}$ ). $\mathrm{Net} \mathrm{CO}_{2}$ assimilation rates $\left(A_{\mathrm{N}}\right)$, stomatal conductance $\left(g_{\mathrm{s}}\right)$, and transpiration rates $(E)$ were estimated using the equations of Von Caemmerer and Farquhar [158]. The SPAD index was nondestructively measured at midday on one 
leaf per plant using a handheld SPAD 502 meter (Minolta, Osaka, Japan). This index provides an estimation of leaf chlorophyll content [159]. On each plant, averaged SPAD values were calculated from three readings along the leaf. Plant hydraulic conductance $\left(\mathrm{K}_{\mathrm{h}}, \mathrm{mmol} \mathrm{H} \mathrm{H}_{2} \mathrm{O} \cdot \mathrm{m}^{-2} \cdot \mathrm{s}^{-1} \cdot \mathrm{MPa}^{-1}\right)$ was calculated using Poiseuille's law analogy for the soil-plant-atmosphere continuum [160].

$$
E_{\text {plant }}=\left(\Psi_{M D}-\Psi_{\mathrm{PD}}\right) \times K_{h}
$$

where $\Psi_{\mathrm{MD}}$ and $\Psi_{\mathrm{PD}}$ are the midday and predawn water potential (MPa), and $\mathrm{E}_{\text {plant }}$ is the transpiration rate expressed as $\mathrm{mmol} \mathrm{H}_{2} \mathrm{O} \cdot \mathrm{m}^{-2} \cdot \mathrm{s}^{-1}$.

Plant transpiration was calculated as the weight decrease between predawn and midday (pots were covered with plastic to avoid evaporation). Plant foliar area was calculated to convert water uptake into transpiration rate.

After completing the set of physiological measurements, four plants from each water treatment were removed from pots and divided into leaves, stems, and roots. Obtained samples were put in paper envelopes and placed in an oven at $80{ }^{\circ} \mathrm{C}$ until reaching a constant weight that was assumed to be dry weight.

\subsection{RNA Extraction}

Avocado roots from control, mild-WS, and severe-WS plants were harvested at $t_{1}$ and $t_{2}$. Three biological replicates per timepoint, in which each biological replicate consisted of three plants $(n=9)$, were used for RNA extraction in each experimental group. RNA from ground root tissue was extracted using the CTAB extraction method [161] with modification described by Zumaquero et al. [21]. RNA parameters and integrity were checked using a NanoDrop ${ }^{\circledR N D}$-1000 (Nanodrop Technologies Inc., Wilmington, DE, USA) spectrophotometer based on the A260/280 and A260/230 wavelength ratios and running samples on a $2 \%$ agarose gel. RNA samples were treated with a DNase treatment with $1 \mathrm{U}$ of RNase-free DNase (Thermo Scientific, Life Technologies Inc., Carlsbad, CA, USA), $1 \mu \mathrm{L}$ of $10 \times$ reaction buffer with $\mathrm{MgCl}_{2}, 1 \mu \mathrm{g}$ of RNA, $0.5 \mu \mathrm{L}$ of RiboLock RNase Inhibitor (Thermo Scientific Inc., CA, USA), and diethylpyrocarbonate-treated water to a final volume of $10 \mu \mathrm{L}$ in all RNA samples. The mixture was incubated according to the manufacturer's instructions at $37^{\circ} \mathrm{C}$ for $45 \mathrm{~min}$ followed by the addition of $1 \mu \mathrm{L}$ of $50 \mathrm{mM}$ EDTA and incubation at $65^{\circ} \mathrm{C}$ for $10 \mathrm{~min}$ according to the manufacturer's instructions.

\subsection{Microarray Analysis}

Microarray hybridizations were carried out using a custom microarray (GEO accession GPL21856) as previously described by Reeksting et al. [20]. For mild-WS plants, three biological replicate hybridizations of water treatment vs. control samples were performed, while two biological replicate hybridizations of water treatment vs. control samples were performed for severe-WS. Microarray data were statistically analyzed using the LIMMA (linear models for microarray data) package in the $R$ version 3.1.0 environment $(R$ Foundation for Statistical Computing) as described in Reeksting et al. [20]. The $p$-values were corrected for multiple testing by the false discovery rate (FDR) method. To determine concordance between biological replicates, a standard pairwise Pearson correlation $(r)$ was performed using normalized M-values. In this study, targets were defined as differentially expressed genes (DEG) if the adjusted $p$-value was less than or equal to $0.05(p \leq 0.05)$ and the $\log _{2}$ ratio $\geq 1$, or the $\log _{2}$ ratio $\leq 1$. The data from this experiment are available from the NCBI Gene Expression Omnibus under accession number GSE151051.

\subsection{Functional Annotation and Clustering}

The software suite Blast2GI (B2G: http:/ / www.blast2go.com. accessed on 1 September 2020) was used to assign Gene Ontology (GO) terms describing biological processes, molecular functions, and cellular components, as well as to perform functional annotation and functional enrichment. A reduction to the most specific terms was applied using the software default parameters and a $p$-value cutoff of 0.05 . Genes with similar expression 
profiles across all three biological samples were identified by a hierarchical clustering analysis of their expression values. The results were then processed with the function hclust, from the stats package (R Core Team. 2017), to calculate Person correlation and to perform a linkage analysis. The dendrograms were plotted as a heatmap with the heatmap.2 function from gplots [162], and an R color Brewer [163] schema was applied in order to facilitate visualization. A unique expression profile was used to define each distinctive cluster of contigs (represented by the dendrogram rows) using cutree, from the stats package (R Core Team. 2017).

\subsection{Quantitative Real-Time PCR}

Quantitative real-time PCR (qRT-PCR) was used to validate microarray results. Singlestranded cDNA was synthesized using an iScript Reverse Transcription Supermix kit (Bio-Rad Laboratories Inc., California, USA). DNA contamination was checked by PCR using gene specific primers F3H-F (5'-TCTGATTTCGGAGATGACTCGC- $\left.3^{\prime}\right)$ and F3HR (5'-TGTAGACTTGGGCCACCTCTTT-3'), which flank an intron of the flavanone 3hydroxylase (F3H) gene. PCR amplifications were carried out using first-strand cDNA as the template as previously described by Engelbrecht and van den Berg [164].

Primer sequences for amplification of the endogenous control gene (actin gene) and 13 avocado genes were designed using Primer 3 software (http:/ / bioinfo.ut.ee/primer3-0.4.0/. accessed on 1 September 2020) (Table S1). qRT-PCR was performed following the methodology detailed in Zumaquero et al. [21]. All reactions were carried out in triplicate, and relative quantification of the expression levels was analyzed using the comparative $\mathrm{Ct}$ method [165].

\subsection{Statistical Analysis}

Statistical analyses were performed using the analytical software STATISTICA 7 (StatSoft Inc., OK, USA). Analysis of variance (ANOVA) was used for assessing significant differences $(p<0.05)$ among treatments in physiological variables. Normality and homogeneity assumptions for ANOVA were tested using the Kolmogorov-Smirnov and the Cochran's C test, respectively. Pairwise comparisons of the means were done using Fisher's least significant difference (LSD) test. Statistics for qRT-PCR data were tested using Student's $t$-test.

Supplementary Materials: The following are available online at https:/ /www.mdpi.com/article/ 10.3390/plants10102077/s1. Table S1. qRT-PCR primer sequences used in this study.

Author Contributions: Formal analysis, M.A. and N.A.O.; funding acquisition, M.-F.E. and P.C.; investigation, M.-O.G., Z.A., v.d.B.N., E.P.-R., M.-F.E., and P.C.; methodology, M.-O.G., N.A.O., v.d.B.N., M.-F.E., and P.C.; writing—original draft, M.-O.G.; writing—review and editing, M.-F.E. and P.C. All authors have read and agreed to the published version of the manuscript.

Funding: This research was supported by the RTA2017-00040-00-00 (INIA-AEI) and AVA2019.008 projects ( $20 \%$ Junta de Andalucía, $80 \%$ FEDER). The funding bodies had no role in the design of the study, in the collection, analysis, and interpretation of data, or in writing the manuscript. C. Pliego is currently supported by an INIA-CCAA contract, co-financed by INIA (20\%) and FEDER (80\%).

Data Availability Statement: All data generated or analyzed during this study are included in this published article. The data from this study are available from the NCBI Gene Expression Omnibus under accession number GSE151051.

Acknowledgments: The authors would like to thank J. Engelbrecht, V. Swart, T Duong, and F. Pliego for their support at the laboratory and valuable comments on experimental design.

Conflicts of Interest: The authors declare no conflict of interest.

Author Contributions: M.-O.G. is a graduate student at the PhD Program of Advanced Biotechnology, University of Málaga. 


\section{References}

1. Walter, J.; Nagy, L.; Hein, R.; Rascher, U.; Beierkuhnlein, C.; Willner, E.; Jentsch, A. Do plants remember drought? Hints towards a drought-memory in grasses. Environ. Exp. Bot. 2011, 71, 34-40. [CrossRef]

2. Allen, C.D.; Breshears, D.D.; McDowell, N.G. On underestimation of global vulnerability to tree mortality and forest die-off from hotter drought in the Anthropocene. Ecosphere 2015, 6, 129. [CrossRef]

3. Nardini, A.; Gullo, M.A.L.; Trifilò, P.; Salleo, S. The challenge of the Mediterranean climate to plant hydraulics: Responses and adaptations. Environ. Exp. Bot. 2014, 103, 68-79. [CrossRef]

4. Purseglove, J.W. Persea americana Mill. In Tropical Crops: Dicotyledons; Longmans, Green and Co. Ltd.: London, UK, 1968; pp. 192-198.

5. Moreno-Ortega, G.; Pliego, C.; Sarmiento, D.; Barceló, A.; Martínez-Ferri, E. Yield and fruit quality of avocado trees under different regimes of water supply in the subtropical coast of Spain. Agric. Water Manag. 2019, 221, 192-201. [CrossRef]

6. Acosta-Rangel, A.; Ávila-Lovera, E.; De Guzman, M.E.; Torres, L.; Haro, R.; Arpaia, M.L.; Focht, E.; Santiago, L.S. Evaluation of leaf carbon isotopes and functional traits in avocado reveals water-use efficient cultivars. Agric. Ecosyst. Environ. 2018, 263, 60-66. [CrossRef]

7. Kremer-Köhne, S.; Köhne, J.S. 25 years of avocado rootstock development in South Africa. In Proceedings of the VI World Avocado Congress, Viña del Mar, Chile, 12-16 November 2007.

8. Haberman, A.; Tsror, L.; Lazare, S.; Hazanovsky, M.; Lebiush, S.; Zipori, I.; Busatn, A.; Simenski, E.; Dag, A. Management of Verticillium Wilt of Avocado Using Tolerant Rootstocks. Plants 2020, 9, 531. [CrossRef] [PubMed]

9. Acosta-Rangel, A.M.; Li, R.; Celis, N.; Suarez, D.L.; Santiago, L.S.; Arpaia, M.L.; Mauk, P.A. The physiological response of 'Hass' avocado to salinity as influenced by rootstock. Sci. Hortic. 2019, 256, 108629. [CrossRef]

10. Berg, N.V.D.; Mahomed, W.; Olivier, N.A.; Swart, V.; Crampton, B.G. Transcriptome analysis of an incompatible Persea americanaPhytophthora cinnamomi interaction reveals the involvement of SA- and JA-pathways in a successful defense response. PLoS ONE 2018, 13, e0205705. [CrossRef]

11. Bogeat-Triboulot, M.-B.; Brosche, M.; Renaut, J.; Jouve, L.; LE Thiec, D.; Fayyaz, P.; Vinocur, B.; Witters, E.; Laukens, K.; Teichmann, T.; et al. Gradual Soil Water Depletion Results in Reversible Changes of Gene Expression, Protein Profiles, Ecophysiology, and Growth Performance in Populus euphratica, a Poplar Growing in Arid Regions. Plant Physiol. 2007, 143, 876-892. [CrossRef] [PubMed]

12. Rodrigues, F.A.; de Laia, M.L.; Zingaretti, S.M. Analysis of gene expression profiles under water stress in tolerant and sensitive sugarcane plants. Plant Sci. 2009, 176, 286-302. [CrossRef]

13. Meyer, E.; Aspinwall, M.J.; Lowry, D.B.; Palacio-Mejía, J.D.; Logan, T.L.; Fay, P.A.; Juenger, T.E. Integrating transcriptional, metabolomic, and physiological responses to drought stress and recovery in switchgrass (Panicum virgatum L.). BMC Genom. 2014, 15, 527. [CrossRef] [PubMed]

14. Fox, H.; Doron-Faigenboim, A.; Kelly, G.; Bourstein, R.; Attia, Z.; Zhou, J.; Moshe, Y.; Moshelion, M.; David-Schwartz, R. Transcriptome analysis of Pinus halepensis under drought stress and during recovery. Tree Physiol. 2018, 38, 423-441. [CrossRef]

15. Bielsa, B.; Hewitt, S.; Reyes-Chin-Wo, S.; Dhingra, A.; Rubio-Cabetas, M.J. Identification of water use efficiency related genes in 'Garnem' almond-peach rootstock using time-course transcriptome analysis. PLoS ONE 2018, 13, e0205493. [CrossRef] [PubMed]

16. Zhang, X.; Lei, L.; Lai, J.; Zhao, H.; Song, W. Effects of drought stress and water recovery on physiological responses and gene expression in maize seedlings. BMC Plant Biol. 2018, 18, 1-16. [CrossRef]

17. Singh, D.; Laxmi, A. Transcriptional regulation of drought response: A tortuous network of transcriptional factors. Front. Plant Sci. 2015, 6, 895. [CrossRef]

18. Wang, H.; Wang, H.; Shao, H.; Tang, X. Recent Advances in Utilizing Transcription Factors to Improve Plant Abiotic Stress Tolerance by Transgenic Technology. Front. Plant Sci. 2016, 7, 67. [CrossRef] [PubMed]

19. Zenda, T.; Liu, S.; Wang, X.; Liu, G.; Jin, H.; Dong, A.; Yang, Y.; Duan, H. Key Maize Drought-Responsive Genes and Pathways Revealed by Comparative Transcriptome and Physiological Analyses of Contrasting Inbred Lines. Int. J. Mol. Sci. 2019, $20,1268$. [CrossRef] [PubMed]

20. Reeksting, B.J.; Olivier, N.A.; Berg, N.V.D. Transcriptome responses of an ungrafted Phytophthora root rot tolerant avocado (Persea americana) rootstock to flooding and Phytophthora cinnamomi. BMC Plant Biol. 2016, 16, 1-19. [CrossRef]

21. Zumaquero, A.; Martínez-Ferri, E.; Matas, A.J.; Reeksting, B.; Olivier, N.A.; Pliego-Alfaro, F.; Barceló, A.; Berg, N.V.D.; Pliego, C. Rosellinia necatrix infection induces differential gene expression between tolerant and susceptible avocado rootstocks. PLoS ONE 2019, 14, e0212359. [CrossRef]

22. Martínez-Ferri, E.; Moreno-Ortega, G.; Berg, N.V.D.; Pliego, C. Mild water stress-induced priming enhance tolerance to Rosellinia necatrix in susceptible avocado rootstocks. BMC Plant Biol. 2019, 19, 1-15. [CrossRef]

23. Hsiao, T.C. Plant Responses to Water Stress. Annu. Rev. Plant Physiol. 1973, 24, 519-570. [CrossRef]

24. Scholefield, P.B.; Walcott, J.J.; Kriedemann, P.E.; Ramadasan, A. Some environmental effects on photosynthesis and water relations of avocado leaves. Calif. Avocado Soc. Yearb. 1980, 64, 93-106.

25. Azcón-Bieto, J.; Talón, M. Fundamentos de Fisiología Vegetal, Segunda ed.; Mc Graw-Hill-Interamericana: Madrid, Spain, 2000.

26. Reyes-Santamaría, I.; Terrazas, T.; Barrientos-Priego, A.F.; Trejo, C. Xylem conductivity and vulnerability in cultivars and races of avocado. Sci. Hortic. 2002, 92, 97-105. [CrossRef] 
27. Ruehr, N.K.; Grote, R.; Mayr, S.; Arneth, A. Beyond the extreme: Recovery of carbon and water relations in woody plants following heat and drought stress. Tree Physiol. 2019, 39, 1285-1299. [CrossRef] [PubMed]

28. Mansfield, T.A.; Atkinson, C.J. Stomatal behaviour in water-stressed plants. In Stress Responses in Plants: Adaptation and Acclimation Mechanisms; Wiley-Liss. Inc.: New York, NY, USA, 1990; pp. 241-264.

29. Chaves, M.M.; Zarrouk, O.; Francisco, R.; Costa, J.; Santos, T.; Regalado, A.; Rodrigues, M.L.; Lopes, C. Grapevine under deficit irrigation: Hints from physiological and molecular data. Ann. Bot. 2010, 105, 661-676. [CrossRef]

30. Flexas, J.; Badger, M.; Chow, W.S.; Medrano, H.; Osmond, C.B. Analysis of the Relative Increase in Photosynthetic $\mathrm{O}_{2} \mathrm{Uptake}$ When Photosynthesis in Grapevine Leaves Is Inhibited following Low Night Temperatures and/or Water Stress. Plant Physiol. 1999, 121, 675-684. [CrossRef]

31. Cifre, J.; Bota, J.; Escalona, J.; Medrano, H.; Flexas, J. Physiological tools for irrigation scheduling in grapevine (Vitis vinifera L.): An open gate to improve water-use efficiency? Agric. Ecosyst. Environ. 2005, 106, 159-170. [CrossRef]

32. Arend, M.; Sever, K.; Pflug, E.; Gessler, A.; Schaub, M. Seasonal photosynthetic response of European beech to severe summer drought: Limitation, recovery and post-drought stimulation. Agric. For. Meteorol. 2016, 220, 83-89. [CrossRef]

33. Birami, B.; Gattmann, M.; Heyer, A.G.; Grote, R.; Arneth, A.; Ruehr, N.K. Heat Waves Alter Carbon Allocation and Increase Mortality of Aleppo Pine Under Dry Conditions. Front. For. Glob. Chang. 2018, 1, 8. [CrossRef]

34. Fereres, E.; Soriano, M.A. Deficit irrigation for reducing agricultural water use. J. Exp. Bot. 2007, 58, 147-159. [CrossRef]

35. Vilagrosa, A.; Chirino, E.; Peguero-Pina, J.; Barigah, T.; Cochard, H.; Gil-Pelegrín, E. Xylem Cavitation and Embolism in Plants Living in Water-Limited Ecosystems. In Plant Responses to Drought Stress; Aroca, R., Ed.; Springer: Berlin/Heidelberg, Germany, 2012. [CrossRef]

36. Jackson, R.B.; Sperry, J.S.; Dawson, T.E. Root water uptake and transport: Using physiological processes in global predictions. Trends Plant Sci. 2000, 5, 482-488. [CrossRef]

37. Bartlett, M.K.; Klein, T.; Jansen, S.; Choat, B.; Sack, L. The correlations and sequence of plant stomatal, hydraulic, and wilting responses to drought. Proc. Natl. Acad. Sci. USA 2016, 113, 13098-13103. [CrossRef] [PubMed]

38. Poorter, H.; Niklas, K.J.; Reich, P.; Oleksyn, J.; Poot, P.; Mommer, L. Biomass allocation to leaves, stems and roots: Meta-analyses of interspecific variation and environmental control. New Phytol. 2012, 193, 30-50. [CrossRef] [PubMed]

39. Bhardwaj, A.R.; Joshi, G.; Kukreja, B.; Malik, V.; Arora, P.; Pandey, R.; Shukla, R.N.; Bankar, K.G.; Katiyar-Agarwal, S.; Goel, S.; et al. Global insights into high temperature and drought stress regulated genes by RNA-Seq in economically important oilseed crop Brassica juncea. BMC Plant Biol. 2015, 15, 1-15. [CrossRef]

40. Garg, R.; Shankar, R.; Thakkar, B.; Kudapa, H.; Krishnamurthy, L.; Mantri, N.; Varshney, R.; Bhatia, S.; Jain, M. Transcriptome analyses reveal genotype- and developmental stage-specific molecular responses to drought and salinity stresses in chickpea. Sci. Rep. 2016, 6, 1-15. [CrossRef]

41. Ksouri, N.; Jiménez, S.; Wells, C.E.; Contreras-Moreira, B.; Gogorcena, Y. Transcriptional Responses in Root and Leaf of Prunus persica under Drought Stress Using RNA Sequencing. Front. Plant Sci. 2016, 7, 1715. [CrossRef]

42. Muthusamy, M.; Uma, S.; Backiyarani, S.; Saraswathi, M.S.; Chandrasekar, A. Transcriptomic Changes of Drought-Tolerant and Sensitive Banana Cultivars Exposed to Drought Stress. Front. Plant Sci. 2016, 7, 1609. [CrossRef]

43. Lau, K.H.; Herrera, M.D.R.; Crisovan, E.; Wu, S.; Fei, Z.; Khan, M.A.; Buell, C.R.; Gemenet, D. Transcriptomic analysis of sweet potato under dehydration stress identifies candidate genes for drought tolerance. Plant Direct 2018, 2, e00092. [CrossRef]

44. Ye, G.; Ma, Y.; Feng, Z.; Zhang, X. Transcriptomic analysis of drought stress responses of sea buckthorn (Hippophae rhamnoidessubsp. sinensis) by RNA-Seq. PLoS ONE 2018, 13, e0202213. [CrossRef]

45. Smirnoff, N. The role of active oxygen in the response of plants to water deficit and desiccation. New Phytol. 1993, 125, 27-58. [CrossRef]

46. Bartoli, C.G.; Simontacchi, M.; Tambussi, E.; Beltrano, J.; Montaldi, E.; Puntarulo, S. Drought and watering-dependent oxidative stress: Effect on antioxidant content in Triticum aestivum L. leaves. J. Exp. Bot. 1999, 50, 375-383. [CrossRef]

47. Loggini, B.; Scartazza, A.; Brugnoli, E.; Navari-Izzo, F. Antioxidative Defense System, Pigment Composition, and Photosynthetic Efficiency in Two Wheat Cultivars Subjected to Drought1. Plant Physiol. 1999, 119, 1091-1100. [CrossRef]

48. Ranty, B.; Aldon, D.; Galaud, J.-P. Plant calmodulins and calmodulin-related proteins: Multifaceted relays to decode calcium signals. Plant Signal. Behav. 2006, 1, 96-104. [CrossRef] [PubMed]

49. Srinivasan, T.; Kumar, K.R.R.; Kirti, P.B. Constitutive Expression of a Trypsin Protease Inhibitor Confers Multiple Stress Tolerance in Transgenic Tobacco. Plant Cell Physiol. 2009, 50, 541-553. [CrossRef] [PubMed]

50. Atkinson, N.J.; Lilley, C.J.; Urwin, P.E. Identification of Genes Involved in the Response of Arabidopsis to Simultaneous Biotic and Abiotic Stresses. Plant Physiol. 2013, 162, 2028-2041. [CrossRef]

51. Cristina, M.; Petersen, M.; Mundy, J. Mitogen-Activated Protein Kinase Signaling in Plants. Annu. Rev. Plant Biol. 2010, 61, 621-649. [CrossRef]

52. Zhang, L.; Zhao, H.-K.; Dong, Q.-L.; Zhang, Y.-Y.; Wang, Y.-M.; Li, H.-Y.; Xing, G.-J.; Li, Q.-Y.; Dong, Y.-S. Genome-wide analysis and expression profiling under heat and drought treatments of HSP70 gene family in soybean (Glycine max L.). Front. Plant Sci. 2015, 6, 773. [CrossRef]

53. Gupta, S.C.; Sharma, A.; Mishra, M.; Mishra, R.K.; Chowdhuri, D.K. Heat shock proteins in toxicology: How close and how far? Life Sci. 2010, 86, 377-384. [CrossRef] 
54. De Ollas, C.; Dodd, I.C. Physiological impacts of ABA-JA interactions under water-limitation. Plant Mol. Biol. 2016, 91, 641-650. [CrossRef]

55. Zhang, Z.; Cao, B.; Li, N.; Chen, Z.; Xu, K. Comparative transcriptome analysis of the regulation of ABA signaling genes in different rootstock grafted tomato seedlings under drought stress. Environ. Exp. Bot. 2019, 166, 103814. [CrossRef]

56. Takahashi, F.; Kuromori, T.; Urano, K.; Yamaguchi-Shinozaki, K.; Shinozaki, K. Drought Stress Responses and Resistance in Plants: From Cellular Responses to Long-Distance Intercellular Communication. Front. Plant Sci. 2020, 11, 1407. [CrossRef]

57. Javot, H.; Lauvergeat, V.; Santoni, V.; Martin-Laurent, F.; Güçlü, J.; Vinh, J.; Heyes, J.; Franck, K.I.; Schäffner, A.R.; Bouchez, D.; et al. Role of a Single Aquaporin Isoform in Root Water Uptake. Plant Cell 2003, 15, 509-522. [CrossRef] [PubMed]

58. Sutka, M.; Li, G.; Boudet, J.; Boursiac, Y.; Doumas, P.; Maurel, C. Natural Variation of Root Hydraulics in Arabidopsis Grown in Normal and Salt-Stressed Conditions. Plant Physiol. 2011, 155, 1264-1276. [CrossRef]

59. Islam, A.; Leung, S.; Nikmatullah, A.; Dijkwel, P.P.; McManus, M.T. Kunitz Proteinase Inhibitors Limit Water Stress Responses in White Clover (Trifolium repens L.) Plants. Front. Plant Sci. 2017, 8, 1683. [CrossRef] [PubMed]

60. Clemente, M.; Corigliano, M.G.; Pariani, S.A.; Sánchez-López, E.F.; Sander, V.A.; Ramos-Duarte, V.A. Plant Serine Protease Inhibitors: Biotechnology Application in Agriculture and Molecular Farming. Int. J. Mol. Sci. 2019, 20, 1345. [CrossRef] [PubMed]

61. Malefo, M.; Mathibela, E.; Crampton, B.; Makgopa, M. Investigating the role of Bowman-Birk serine protease inhibitor in Arabidopsis plants under drought stress. Plant Physiol. Biochem. 2020, 149, 286-293. [CrossRef] [PubMed]

62. Iuchi, S.; Kobayashi, M.; Taji, T.; Naramoto, M.; Seki, M.; Kato, T.; Tabata, S.; Kakubari, Y.; Yamaguchi-Shinozaki, K.; Shinozaki, K. Regulation of drought tolerance by gene manipulation of 9-cis-epoxycarotenoid dioxygenase, a key enzyme in abscisic acid biosynthesis in Arabidopsis. Plant J. 2001, 27, 325-333. [CrossRef] [PubMed]

63. He, R.; Zhuang, Y.; Cai, Y.; Agüero, C.B.; Liu, S.; Wu, J.; Deng, S.; Walker, M.A.; Lu, J.; Zhang, Y. Overexpression of 9-cisEpoxycarotenoid Dioxygenase Cisgene in Grapevine Increases Drought Tolerance and Results in Pleiotropic Effects. Front. Plant Sci. 2018, 9, 970. [CrossRef] [PubMed]

64. Molinari, M.D.C.; Fuganti-Pagliarini, R.; Marin, S.R.R.; Ferreira, L.C.; Barbosa, D.D.A.; Marcolino-Gomes, J.; De Oliveira, M.C.N.; Mertz-Henning, L.M.; Kanamori, N.; Takasaki, H.; et al. Overexpression of AtNCED3 gene improved drought tolerance in soybean in greenhouse and field conditions. Genet. Mol. Biol. 2020, 43, e20190292. [CrossRef]

65. Zhai, H.; Wang, F.; Si, Z.; Huo, J.; Xing, L.; An, Y.; He, S.; Liu, Q. Amyo-inositol-1-phosphate synthase gene, IbMIPS1, enhances salt and drought tolerance and stem nematode resistance in transgenic sweet potato. Plant Biotechnol. J. 2016, 14, 592-602. [CrossRef]

66. Liu, H.; Wang, X.; Zhang, H.; Yang, Y.; Ge, X.; Song, F. A rice serine carboxypeptidase-like gene OsBISCPL1 is involved in regulation of defense responses against biotic and oxidative stress. Gene 2008, 420, 57-65. [CrossRef] [PubMed]

67. Pieczynski, M.; Wyrzykowska, A.; Milanowska, K.; Boguszewska-Mankowska, D.; Zagdanska, B.; Karlowski, W.; Jarmolowski, A.; Szweykowska-Kulinska, Z. Genomewide identification of genes involved in the potato response to drought indicates functional evolutionary conservation with Arabidopsis plants. Plant Biotechnol. J. 2018, 16, 603-614. [CrossRef] [PubMed]

68. Rosado, A.; Schapire, A.L.; Bressan, R.A.; Harfouche, A.; Hasegawa, P.M.; Valpuesta, V.; Botella, M.A. The Arabidopsis Tetratricopeptide Repeat-Containing Protein TTL1 Is Required for Osmotic Stress Responses and Abscisic Acid Sensitivity. Plant Physiol. 2006, 142, 1113-1126. [CrossRef]

69. Kang, J.; Hwang, J.-U.; Lee, M.; Kim, Y.-Y.; Assmann, S.M.; Martinoia, E.; Lee, Y. PDR-type ABC transporter mediates cellular uptake of the phytohormone abscisic acid. Proc. Natl. Acad. Sci. USA 2010, 107, 2355-2360. [CrossRef] [PubMed]

70. Kuromori, T.; Miyaji, T.; Yabuuchi, H.; Shimizu, H.; Sugimoto, E.; Kamiya, A.; Moriyama, Y.; Shinozaki, K. ABC transporter AtABCG25 is involved in abscisic acid transport and responses. Proc. Natl. Acad. Sci. USA 2010, 107, 2361-2366. [CrossRef]

71. Ali, S.; Ganai, B.A.; Kamili, A.N.; Bhat, A.A.; Mir, Z.; Bhat, J.A.; Tyagi, A.; Islam, S.T.; Mushtaq, M.; Yadav, P.; et al. Pathogenesisrelated proteins and peptides as promising tools for engineering plants with multiple stress tolerance. Microbiol. Res. 2018, 212-213, 29-37. [CrossRef] [PubMed]

72. Wang, H.; Wang, Z.; Zhang, M.; Jia, B.; Heng, W.; Ye, Z.; Zhu, L.; Xu, X. Transcriptome sequencing analysis of two different genotypes of Asian pear reveals potential drought stress genes. Tree Genet. Genomes 2018, 14, 40. [CrossRef]

73. Gahlaut, V.; Jaiswal, V.; Kumar, A.; Gupta, P.K. Transcription factors involved in drought tolerance and their possible role in developing drought tolerant cultivars with emphasis on wheat (Triticum aestivum L.). Theor. Appl. Genet. 2016, 129, $2019-2042$. [CrossRef] [PubMed]

74. Lindemose, S.; O'Shea, C.; Jensen, M.K.; Skriver, K. Structure, Function and Networks of Transcription Factors Involved in Abiotic Stress Responses. Int. J. Mol. Sci. 2013, 14, 5842-5878. [CrossRef]

75. Olsen, A.N.; Ernst, H.A.; Leggio, L.L.; Skriver, K. NAC transcription factors: Structurally distinct, functionally diverse. Trends Plant Sci. 2005, 10, 79-87. [CrossRef]

76. Seo, P.J.; Xiang, F.; Qiao, M.; Park, J.-Y.; Na Lee, Y.; Kim, S.-G.; Lee, Y.-H.; Park, W.J.; Park, C.-M. The MYB96 Transcription Factor Mediates Abscisic Acid Signaling during Drought Stress Response in Arabidopsis. Plant Physiol. 2009, 151, 275-289. [CrossRef]

77. Yang, X.; Kim, M.Y.; Ha, J.; Lee, S.-H. Overexpression of the Soybean NAC Gene GmNAC109 Increases Lateral Root Formation and Abiotic Stress Tolerance in Transgenic Arabidopsis Plants. Front. Plant Sci. 2019, 10, 1036. [CrossRef] [PubMed]

78. Gaoming, S.-Q.; Chen, M.; Xu, Z.-S.; Zhao, C.-P.; Li, L.; Xu, H.-J.; Tang, Y.-M.; Zhao, X.; Ma, Y.-Z. The soybean GmbZIP1 transcription factor enhances multiple abiotic stress tolerances in transgenic plants. Plant Mol. Biol. 2011, 75, 537-553. [CrossRef]

79. Yin, M.; Wang, Y.; Zhang, L.; Li, J.; Quan, W.; Yang, L.; Wang, Q.; Chan, Z. The Arabidopsis Cys2/His2 zinc finger transcription factor ZAT18 is a positive regulator of plant tolerance to drought stress. J. Exp. Bot. 2017, 68, 2991-3005. [CrossRef] [PubMed] 
80. Han, G.; Lu, C.; Guo, J.; Qiao, Z.; Sui, N.; Qiu, N.; Wang, B. C2H2 Zinc Finger Proteins: Master Regulators of Abiotic Stress Responses in Plants. Front. Plant Sci. 2020, 11, 115. [CrossRef]

81. Guo, M.; Liu, J.-H.; Ma, X.; Luo, D.-X.; Gong, Z.-H.; Lu, M.-H. The Plant Heat Stress Transcription Factors (HSFs): Structure, Regulation, and Function in Response to Abiotic Stresses. Front. Plant Sci. 2016, 7, 114. [CrossRef]

82. Perotti, M.F.; Ribone, P.A.; Chan, R.L. Plant transcription factors from the homeodomain-leucine zipper family I. Role in development and stress responses. IUBMB Life 2017, 69, 280-289. [CrossRef]

83. Wu, Y.; Deng, Z.; Lai, J.; Zhang, Y.; Yang, C.; Yin, B.; Zhao, Q.; Zhang, L.; Li, Y.; Yang, C.; et al. Dual function of Arabidopsis ATAF1 in abiotic and biotic stress responses. Cell Res. 2009, 19, 1279-1290. [CrossRef]

84. Xu, Z.-Y.; Kim, S.Y.; Hyeon, D.Y.; Kim, D.H.; Dong, T.; Park, Y.; Jin, J.B.; Joo, S.-H.; Hong, J.C.; Hwang, D.; et al. The Arabidopsis NAC Transcription Factor ANAC096 Cooperates with bZIP-Type Transcription Factors in Dehydration and Osmotic Stress Responses. Plant Cell 2013, 25, 4708-4724. [CrossRef]

85. Nakashima, K.; Yamaguchi-Shinozaki, K.; Shinozaki, K. The transcriptional regulatory network in the drought response and its crosstalk in abiotic stress responses including drought, cold, and heat. Front. Plant Sci. 2014, 5, 170. [CrossRef]

86. Sakuraba, Y.; Kim, Y.-S.; Han, S.-H.; Lee, B.-D.; Paek, N.-C. The Arabidopsis Transcription Factor NAC016 Promotes Drought Stress Responses by Repressing AREB1 Transcription through a Trifurcate Feed-Forward Regulatory Loop Involving NAP. Plant Cell 2015, 27, 1771-1787. [CrossRef] [PubMed]

87. Ehong, Y.; Ezhang, H.; Ehuang, L.; Eli, D.; Esong, F. Overexpression of a Stress-Responsive NAC Transcription Factor Gene ONAC022 Improves Drought and Salt Tolerance in Rice. Front. Plant Sci. 2016, 7, 4. [CrossRef]

88. Rushton, P.J.; Somssich, I.; Ringler, P.; Shen, Q.J. WRKY transcription factors. Trends Plant Sci. 2010, 15, 247-258. [CrossRef] [PubMed]

89. Yu, Y.-T.; Wu, Z.; Lu, K.; Bi, C.; Liang, S.; Wang, X.-F.; Zhang, D.-P. Overexpression of the MYB37 transcription factor enhances abscisic acid sensitivity, and improves both drought tolerance and seed productivity in Arabidopsis thaliana. Plant Mol. Biol. 2016, 90, 267-279. [CrossRef] [PubMed]

90. Cheng, X.; Xiong, R.; Yan, H.; Gao, Y.; Liu, H.; Wu, M.; Xiang, Y. The trihelix family of transcription factors: Functional and evolutionary analysis in Moso bamboo (Phyllostachys edulis). BMC Plant Biol. 2019, 19, 1-20. [CrossRef]

91. Li, J.; Zhang, M.; Sun, J.; Mao, X.; Wang, J.; Wang, J.; Liu, H.; Zheng, H.; Zhen, Z.; Zhao, H.; et al. Genome-Wide Characterization and Identification of Trihelix Transcription Factor and Expression Profiling in Response to Abiotic Stresses in Rice (Oryza sativa L.). Int. J. Mol. Sci. 2019, 20, 251. [CrossRef]

92. Magwanga, R.O.; Kirungu, J.N.; Lu, P.; Yang, X.; Dong, Q.; Cai, X.; Xu, Y.; Wang, X.; Zhou, Z.; Hou, Y.; et al. Genome wide identification of the trihelix transcription factors and overexpression of Gh_A05G2067 (GT-2), a novel gene contributing to increased drought and salt stresses tolerance in cotton. Physiol. Plant. 2019, 167, 447-464. [CrossRef]

93. Qin, X.; Zeevaart, J.A. Overexpression of a 9-cis-Epoxycarotenoid Dioxygenase Gene in Nicotiana plumbaginifolia Increases Abscisic Acid and Phaseic Acid Levels and Enhances Drought Tolerance. Plant Physiol. 2002, 128, 544-551. [CrossRef]

94. Huang, Y.; Guo, Y.; Liu, Y.; Zhang, F.; Wang, Z.; Wang, H.; Wang, F.; Li, D.; Mao, D.; Luan, S.; et al. 9-cis-Epoxycarotenoid Dioxygenase 3 Regulates Plant Growth and Enhances Multi-Abiotic Stress Tolerance in Rice. Front. Plant Sci. $2018,9,162$. [CrossRef]

95. Huang, Y.; Jiao, Y.; Xie, N.; Guo, Y.; Zhang, F.; Xiang, Z.; Wang, R.; Wang, F.; Gao, Q.; Tian, L.; et al. OsNCED5, a 9-cisepoxycarotenoid dioxygenase gene, regulates salt and water stress tolerance and leaf senescence in rice. Plant Sci. 2019, 287, 110188. [CrossRef]

96. Skubacz, A.; Daszkowska-Golec, A.; Szarejko, I. The Role and Regulation of ABI5 (ABA-Insensitive 5) in Plant Development, Abiotic Stress Responses and Phytohormone Crosstalk. Front. Plant Sci. 2016, 7, 1884. [CrossRef] [PubMed]

97. Collin, A.; Daszkowska-Golec, A.; Kurowska, M.; Szarejko, I. Barley ABI5 (Abscisic Acid INSENSITIVE 5) Is Involved in Abscisic Acid-Dependent Drought Response. Front. Plant Sci. 2020, 11, 1138. [CrossRef]

98. He, Z.; Wu, J.; Sun, X.; Dai, M. The Maize Clade A PP2C Phosphatases Play Critical Roles in Multiple Abiotic Stress Responses. Int. J. Mol. Sci. 2019, 20, 3573. [CrossRef] [PubMed]

99. Jung, C.; Nguyen, N.H.; Cheong, J.-J. Transcriptional Regulation of Protein Phosphatase 2C Genes to Modulate Abscisic Acid Signaling. Int. J. Mol. Sci. 2020, 21, 9517. [CrossRef] [PubMed]

100. Das-Chatterjee, A.; Goswami, L.; Maitra, S.; Dastidar, K.G.; Ray, S.; Majumder, A.L. Introgression of a novel salt-tolerant L-myoinositol 1-phosphate synthase from Porteresia coarctata (Roxb.) Tateoka (PcINO1) confers salt tolerance to evolutionary diverse organisms. FEBS Lett. 2006, 580, 3980-3988. [CrossRef]

101. Kaur, H.; Verma, P.; Petla, B.P.; Rao, V.; Saxena, S.C.; Majee, M. Ectopic expression of the ABA-inducible dehydration-responsive chickpea 1-myo-inositol 1-phosphate synthase 2 (CaMIPS2) in Arabidopsis enhances tolerance to salinity and dehydration stress. Planta 2013, 237, 321-335. [CrossRef] [PubMed]

102. Tan, J.; Wang, C.; Xiang, B.; Han, R.; Guo, Z. Hydrogen peroxide and nitric oxide mediated cold- and dehydration-inducedmyoinositol phosphate synthase that confers multiple resistances to abiotic stresses. Plant Cell Environ. 2013, 36, 288-299. [CrossRef]

103. Goswami, L.; Sengupta, S.; Mukherjee, S.; Ray, S.; Mukherjee, R.; Majumder, A.L. Targeted expression of L-myo- inositol 1-phosphate synthase from Porteresia coarctata (Roxb.) Tateoka confers multiple stress tolerance in transgenic crop plants. J. Plant Biochem. Biotechnol. 2014, 23, 316-330. [CrossRef] 
104. Padmalatha, K.V.; Dhandapani, G.; Kanakachari, M.; Kumar, S.; Dass, A.; Patil, D.P.; Rajamani, V.; Kumar, K.; Pathak, R.; Rawat, B.; et al. Genome-wide transcriptomic analysis of cotton under drought stress reveal significant down-regulation of genes and pathways involved in fibre elongation and up-regulation of defense responsive genes. Plant Mol. Biol. 2012, 78, 223-246. [CrossRef]

105. Ji, W.; Zhu, Y.; Li, Y.; Yang, L.; Zhao, X.; Cai, H.; Bai, X. Over-expression of a glutathione S-transferase gene, GsGST, from wild soybean (Glycine soja) enhances drought and salt tolerance in transgenic tobacco. Biotechnol. Lett. 2010, 32, 1173-1179. [CrossRef]

106. Chen, J.-H.; Jiang, H.-W.; Hsieh, E.-J.; Chen, H.-Y.; Chien, C.-T.; Hsieh, H.-L.; Lin, T.-P. Drought and Salt Stress Tolerance of an Arabidopsis Glutathione S-Transferase U17 Knockout Mutant Are Attributed to the Combined Effect of Glutathione and Abscisic Acid. Plant Physiol. 2012, 158, 340-351. [CrossRef]

107. Nianiou-Obeidat, I.; Madesis, P.; Kissoudis, C.; Voulgari, G.; Chronopoulou, E.; Tsaftaris, A.; Labrou, N.E. Plant glutathione transferase-mediated stress tolerance: Functions and biotechnological applications. Plant Cell Rep. 2017, 36, 791-805. [CrossRef] [PubMed]

108. Senthil-Kumar, M.; Hema, R.; Suryachandra, T.R.; Ramegowda, H.; Gopalakrishna, R.; Rama, N.; Udayakumar, M.; Mysore, K.S. Functional characterization of three water deficit stress-induced genes in tobacco and Arabidopsis: An approach based on gene down regulation. Plant Physiol. Biochem. 2010, 48, 35-44. [CrossRef] [PubMed]

109. Hatmi, S.; Gruau, C.; Trotel-Aziz, P.; Villaume, S.; Rabenoelina, F.; Baillieul, F.; Eullaffroy, P.; Clément, C.; Ferchichi, A.; Aziz, A. Drought stress tolerance in grapevine involves activation of polyamine oxidation contributing to improved immune response and low susceptibility to Botrytis cinerea. J. Exp. Bot. 2015, 66, 775-787. [CrossRef] [PubMed]

110. Fraudentali, I.; Rodrigues-Pousada, R.; Angelini, R.; Ghuge, S.; Cona, A. Plant Copper Amine Oxidases: Key Players in Hormone Signaling Leading to Stress-Induced Phenotypic Plasticity. Int. J. Mol. Sci. 2021, 22, 5136. [CrossRef]

111. Pospíšilová, H.; Jiskrova, E.; Vojta, P.; Mrízová, K.; Kokáš, F.; Čudejková, M.M.; Bergougnoux, V.; Plíhal, O.; Klimešová, J.; Novak, O.; et al. Transgenic barley overexpressing a cytokinin dehydrogenase gene shows greater tolerance to drought stress. New Biotechnol. 2016, 33, 692-705. [CrossRef] [PubMed]

112. Chen, L.; Zhao, J.; Song, J.C.; Jameson, P.E. Cytokinin dehydrogenase: A genetic target for yield improvement in wheat. Plant Biotechnol. J. 2020, 18, 614-630. [CrossRef] [PubMed]

113. Hai, N.N.; Chuong, N.N.; Tu, N.H.C.; Kisiala, A.; Hoang, X.L.T.; Thao, N.P. Role and Regulation of Cytokinins in Plant Response to Drought Stress. Plants 2020, 9, 422. [CrossRef] [PubMed]

114. Lim, C.W.; Han, S.-W.; Hwang, I.S.; Kim, D.S.; Hwang, B.K.; Lee, S.C. The Pepper Lipoxygenase CaLOX1 Plays a Role in Osmotic, Drought and High Salinity Stress Response. Plant Cell Physiol. 2015, 56, 930-942. [CrossRef]

115. Xing, Q.; Zhang, X.; Li, Y.; Shao, Q.; Cao, S.; Wang, F.; Qi, H. The lipoxygenase CmLOX13 from oriental melon enhanced severe drought tolerance via regulating ABA accumulation and stomatal closure in Arabidopsis. Environ. Exp. Bot. 2019, 167, 103815. [CrossRef]

116. Xing, Q.; Liao, J.; Cao, S.; Li, M.; Lv, T.; Qi, H. CmLOX10 positively regulates drought tolerance through jasmonic acid -mediated stomatal closure in oriental melon (Cucumis melo var. makuwa Makino). Sci. Rep. 2020, 10, 1-14. [CrossRef]

117. Zeng, L.; Deng, R.; Guo, Z.; Yang, S.; Deng, X. Genome-wide identification and characterization of Glyceraldehyde-3-phosphate dehydrogenase genes family in wheat (Triticum aestivum). BMC Genom. 2016, 17, 1-10. [CrossRef] [PubMed]

118. Li, X.; Wei, W.; Li, F.; Zhang, L.; Deng, X.; Liu, Y.; Yang, S. The Plastidial Glyceraldehyde-3-Phosphate Dehydrogenase Is Critical for Abiotic Stress Response in Wheat. Int. J. Mol. Sci. 2019, 20, 1104. [CrossRef] [PubMed]

119. Hu, Y.; Li, W.C.; Xu, Y.Q.; Li, G.J.; Liao, Y.; Fu, F.-L. Differential expression of candidate genes for lignin biosynthesis under drought stress in maize leaves. J. Appl. Genet. 2009, 50, 213-223. [CrossRef] [PubMed]

120. Li, Z.; Peng, Y.; Ma, X. Different response on drought tolerance and post-drought recovery between the small-leafed and the large-leafed white clover (Trifolium repens L.) associated with antioxidative enzyme protection and lignin metabolism. Acta Physiol. Plant. 2013, 35, 213-222. [CrossRef]

121. Liu, W.; Jiang, Y.; Wang, C.; Zhao, L.; Jin, Y.; Xing, Q.; Li, M.; Lv, T.; Qi, H. Lignin synthesized by CmCAD2 and CmCAD3 in oriental melon (Cucumis melo L.) seedlings contributes to drought tolerance. Plant Mol. Biol. 2020, 103, 689-704. [CrossRef]

122. Aguayo, M.F.; Ampuero, D.; Mandujano, P.; Parada, R.; Muñoz, R.; Gallart, M.; Altabella, T.; Cabrera, R.; Stange, C.; Handford, M. Sorbitol dehydrogenase is a cytosolic protein required for sorbitol metabolism in Arabidopsis thaliana. Plant Sci. 2013, 205-206, 63-75. [CrossRef]

123. Jia, Y.; Wong, D.C.; Sweetman, C.; Bruning, J.B.; Ford, C.M. New insights into the evolutionary history of plant sorbitol dehydrogenase. BMC Plant Biol. 2015, 15, 101. [CrossRef]

124. Cha, J.-Y.; Kim, J.Y.; Jung, I.J.; Kim, M.R.; Melencion, A.; Alam, S.S.; Yun, D.-J.; Lee, S.Y.; Kim, M.G.; Kim, W.-Y. NADPH-dependent thioredoxin reductase A (NTRA) confers elevated tolerance to oxidative stress and drought. Plant Physiol. Biochem. 2014, 80, 184-191. [CrossRef]

125. da Fonseca-Pereira, P.; Daloso, D.M.; Gago, J.; Silva, F.M.D.O.; A Condori-Apfata, J.; Florez-Sarasa, I.; Tohge, T.; Reichheld, J.-P.; Nunes-Nesi, A.; Fernie, A.R.; et al. The Mitochondrial Thioredoxin System Contributes to the Metabolic Responses Under Drought Episodes in Arabidopsis. Plant Cell Physiol. 2019, 60, 213-229. [CrossRef]

126. Duan, F.; Ding, J.; Lee, D.; Lu, X.; Feng, Y.-Q.; Song, W. Overexpression of SoCYP85A1, a Spinach Cytochrome p450 Gene in Transgenic Tobacco Enhances Root Development and Drought Stress Tolerance. Front. Plant Sci. 2017, 8, 1909. [CrossRef] [PubMed] 
127. Rao, M.J.; Xu, Y.; Tang, X.; Huang, Y.; Liu, J.; Deng, X.; Xu, Q. CsCYT75B1, a Citrus CYTOCHROME P450 Gene, Is Involved in Accumulation of Antioxidant Flavonoids and Induces Drought Tolerance in Transgenic Arabidopsis. Antioxidants 2020, 9, 161. [CrossRef] [PubMed]

128. Magwanga, R.O.; Lu, P.; Kirungu, J.N.; Dong, Q.; Cai, X.; Zhou, Z.; Wang, X.; Hou, Y.; Xu, Y.; Peng, R.; et al. Knockdown of Cytochrome P450 Genes Gh_D07G1197 and Gh_A13G2057 on Chromosomes D07 and A13 Reveals Their Putative Role in Enhancing Drought and Salt Stress Tolerance in Gossypium hirsutum. Genes 2019, 10, 226. [CrossRef]

129. Islam, T.; Manna, M.; Reddy, M.K. Glutathione Peroxidase of Pennisetum glaucum (PgGPx) Is a Functional Cd2+ Dependent Peroxiredoxin that Enhances Tolerance against Salinity and Drought Stress. PLoS ONE 2015, 10, e0143344. [CrossRef]

130. Csiszár, J.; Gallé, A.; Horváth, E.; Dancsó, P.; Gombos, M.; Váry, Z.; Erdei, L.; Györgyey, J.; Tari, I. Different peroxidase activities and expression of abiotic stress-related peroxidases in apical root segments of wheat genotypes with different drought stress tolerance under osmotic stress. Plant Physiol. Biochem. 2012, 52, 119-129. [CrossRef]

131. Liu, J.-X.; Feng, K.; Duan, A.-Q.; Li, H.; Yang, Q.-Q.; Xu, Z.-S.; Xiong, A.-S. Isolation, purification and characterization of an ascorbate peroxidase from celery and overexpression of the AgAPX1 gene enhanced ascorbate content and drought tolerance in Arabidopsis. BMC Plant Biol. 2019, 19, 1-13. [CrossRef]

132. Zhang, L.; Wu, M.; Teng, Y.; Jia, S.; Yu, D.; Wei, T.; Chen, C.; Song, W. Overexpression of the Glutathione Peroxidase 5 (RcGPX5) Gene From Rhodiola crenulata Increases Drought Tolerance in Salvia miltiorrhiza. Front. Plant Sci. 2019, 9, 1950. [CrossRef] [PubMed]

133. George, S.; Manoharan, D.; Li, J.; Britton, M.; Parida, A. Drought and salt stress in Chrysopogon zizanioides leads to common and specific transcriptomic responses and may affect essential oil composition and benzylisoquinoline alkaloids metabolism. Curr. Plant Biol. 2017, 11-12, 12-22. [CrossRef]

134. Morrell, R.; Sadanandom, A. Dealing with Stress: A Review of Plant SUMO Proteases. Front. Plant Sci. 2019, 10, 1122. [CrossRef]

135. Huang, Y.; Xiao, B.; Xiong, L. Characterization of a stress responsive proteinase inhibitor gene with positive effect in improving drought resistance in rice. Planta 2007, 226, 73-85. [CrossRef]

136. Zhang, X.; Liu, S.; Takano, T. Two cysteine proteinase inhibitors from Arabidopsis thaliana, AtCYSa and AtCYSb, increasing the salt, drought, oxidation and cold tolerance. Plant Mol. Biol. 2008, 68, 131-143. [CrossRef] [PubMed]

137. Budič, M.; Sabotič, J.; Meglič, V.; Kos, J.; Kidrič, M. Characterization of two novel subtilases from common bean (Phaseolus vulgaris L.) and their responses to drought. Plant Physiol. Biochem. 2013, 62, 79-87. [CrossRef] [PubMed]

138. Figueiredo, J.; Silva, M.S.; Figueiredo, A. Subtilisin-like proteases in plant defence: The past, the present and beyond. Mol. Plant Pathol. 2018, 19, 1017-1028. [CrossRef] [PubMed]

139. Grigorova, B.; Vaseva, I.; Demirevska, K.; Feller, U. Expression of selected heat shock proteins after individually applied and combined drought and heat stress. Acta Physiol. Plant. 2011, 33, 2041-2049. [CrossRef]

140. Taji, T.; Ohsumi, C.; Iuchi, S.; Seki, M.; Kasuga, M.; Kobayashi, M.; Yamaguchi-Shinozaki, K.; Shinozaki, K. Important roles of drought- and cold-inducible genes for galactinol synthase in stress tolerance in Arabidopsis thaliana. Plant J. 2002, 29, 417-426. [CrossRef]

141. Zhuo, C.; Wang, T.; Lu, S.; Zhao, Y.; Li, X.; Guo, Z. A cold responsive galactinol synthase gene fromMedicago falcata(MfGolS1) is induced bymyo-inositol and confers multiple tolerances to abiotic stresses. Physiol. Plant. 2013, 149, 67-78. [CrossRef]

142. Vinson, C.C.; Mota, A.P.Z.; Porto, B.N.; Oliveira, T.N.; Sampaio, I.; Lacerda, A.L.; Danchin, E.G.J.; Guimaraes, P.M.; Williams, T.C.R.; Brasileiro, A.C.M. Characterization of raffinose metabolism genes uncovers a wild Arachis galactinol synthase conferring tolerance to abiotic stresses. Sci. Rep. 2020, 10, 1-19. [CrossRef]

143. Hayat, S.; Hayat, Q.; Alyemeni, M.N.; Wani, A.S.; Pichtel, J.; Ahmad, A. Role of proline under changing environments: A review. Plant Signal. Behav. 2012, 7, 1456-1466. [CrossRef]

144. Jarzyniak, K.; Jasiå,Ski, M. Membrane transporters and drought resistance-A complex issue. Front. Plant Sci. 2014, 5, 687. [CrossRef]

145. Kaur, G.; Asthir, B. Proline: A key player in plant abiotic stress tolerance. Biol. Plant. 2015, 59, 609-619. [CrossRef]

146. Li, Y.C.; Meng, F.R.; Zhang, C.Y.; Zhang, N.; Sun, M.S.; Ren, J.P.; Bin Niu, H.; Wang, X.; Yin, J. Comparative analysis of water stress-responsive transcriptomes in drought-susceptible and -tolerant wheat (Triticum aestivum L.). J. Plant Biol. 2012, 55, 349-360. [CrossRef]

147. Jones, L.; McQueen-Mason, S. A role for expansins in dehydration and rehydration of the resurrection plant Craterostigma plantagineum. FEBS Lett. 2004, 559, 61-65. [CrossRef]

148. Li, F.; Han, Y.; Feng, Y.; Xing, S.; Zhao, M.; Chen, Y.; Wang, W. Expression of wheat expansin driven by the RD29 promoter in tobacco confers water-stress tolerance without impacting growth and development. J. Biotechnol. 2013, 163, 281-291. [CrossRef]

149. Cho, S.K.; Kim, J.E.; Park, J.-A.; Eom, T.J.; Kim, W.T. Constitutive expression of abiotic stress-inducible hot pepperCaXTH3, which encodes a xyloglucan endotransglucosylase/hydrolase homolog, improves drought and salt tolerance in transgenicArabidopsisplants. FEBS Lett. 2006, 580, 3136-3144. [CrossRef] [PubMed]

150. Choi, J.Y.; Seo, Y.S.; Kim, S.J.; Kim, W.T.; Shin, J.S. Constitutive expression of CaXTH3, a hot pepper xyloglucan endotransglucosylase/hydrolase, enhanced tolerance to salt and drought stresses without phenotypic defects in tomato plants (Solanum lycopersicum cv. Dotaerang). Plant Cell Rep. 2011, 30, 867-877. [CrossRef]

151. Dong, J. Isolation of a novel xyloglucan endotransglucosylase (OsXET9) gene from rice and analysis of the response of this gene to abiotic stresses. Afr. J. Biotechnol. 2011, 10, 17424-17434. [CrossRef] 
152. Blum, A. Osmotic adjustment is a prime drought stress adaptive engine in support of plant production. Plant Cell Environ. 2017, 40, 4-10. [CrossRef]

153. Turner, N.C. Turgor maintenance by osmotic adjustment: 40 years of progress. J. Exp. Bot. 2018, 69, 3223-3233. [CrossRef] [PubMed]

154. Le Gall, H.; Philippe, F.; Domon, J.-M.; Gillet, F.; Pelloux, J.; Rayon, C. Cell Wall Metabolism in Response to Abiotic Stress. Plants 2015, 4, 112-166. [CrossRef]

155. Fanourakis, D.; Nikoloudakis, N.; Pappi, P.; Markakis, E.; Doupis, G.; Charova, S.N.; Delis, C.; Tsaniklidis, G. The Role of Proteases in Determining Stomatal Development and Tuning Pore Aperture: A Review. Plants 2020, 9, 340. [CrossRef]

156. Frolich, E.F.; Platt, R.G. Use of the etiolation technique in rooting avocado cuttings. Calif. Avocado Soc. Yearb. 1972, 55, 97-109.

157. Hsiao, T.C. Measurements of plant water status. In Irrigation of Agricultural Crops; Monograph No. 30; Stewart, B.A., Nielsen, D.R., Eds.; American Society of Agronomy: Madison, WI, USA, 1990; pp. 243-279.

158. Von Caemmerer, S.; Farquhar, G. Some relationships between the biochemistry of photosynthesis and the gas exchange of leaves. Planta 1981, 153, 376-387. [CrossRef]

159. Uddling, J.; Gelang-Alfredsson, J.; Piikki, K.; Pleijel, H. Evaluating the relationship between leaf chlorophyll concentration and SPAD-502 chlorophyll meter readings. Photosynth. Res. 2007, 91, 37-46. [CrossRef]

160. Lovisolo, C.; Hartung, W.; Schubert, A. Whole-plant hydraulic conductance and root-to-shoot flow of abscisic acid are independently affected by water stress in grapevines. Funct. Plant Biol. 2002, 29, 1349-1356. [CrossRef] [PubMed]

161. Chang, S.; Puryear, J.; Cairney, J. A simple and efficient method for isolating RNA from pine trees. Plant Mol. Biol. Rep. 1993, 11, 113-116. [CrossRef]

162. Warnes, G.R.; Bolker, B.; Bonebakker, L.; Gentleman, R.; Liaw, W.H.A.; Lumley, T.; Maechler, M.; Magnusson, A.; Moeller, S.; Schwartz, M.; et al. gplots: Various R Programming Tools for Plotting Data. R Package Version 3.0.1. 2016. Available online: https:/ / cran.r-project.org/web/packages/gplots/index.html (accessed on 30 April 2018).

163. Neuwirth, E. RcolorBrewer: Colorbrewer Palettes. R Package Version 1.1-2. 2014. Available online: https://CRAN.R-project.org/ package $=$ RColorBrewer (accessed on 1 April 2018).

164. Engelbrecht, J.; Berg, N.V.D. Expression of defence-related genes against Phytophthora cinnamomi in five avocado rootstocks. S. Afr. J. Sci. 2013, 109, 1-8. [CrossRef]

165. Pfaffl, M.W. A new mathematical model for relative quantification in real-time RT-PCR. Nucleic Acids Res. 2001, 29, 45e. [CrossRef] [PubMed] 